\title{
Analysis of the Well-Being Levels of Students in Spain and Finland through Interval Multiobjective Linear Programming
}

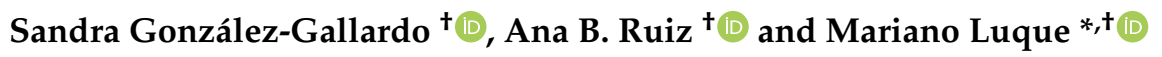 \\ Department of Applied Economics (Mathematics), University of Málaga, Calle Ejido 6, 29071 Málaga, Spain; \\ sandragg@uma.es (S.G.-G.); abruiz@uma.es (A.B.R.) \\ * Correspondence: mluque@uma.es; Tel.: +34-952-131-173 \\ + These authors contributed equally to this work.
}

Citation: González-Gallardo, S.;

Ruiz, A.B.; Luque, M. Analysis of the Well-Being Levels of Students in Spain and Finland through Interval Multiobjective Linear Programming. Mathematics 2021, 9, 1628. https:// doi.org/10.3390/math9141628

Academic Editor: Víctor Yepes

Received: 4 June 2021

Accepted: 2 July 2021

Published: 10 July 2021

Publisher's Note: MDPI stays neutral with regard to jurisdictional claims in published maps and institutional affiliations.

Copyright: (c) 2021 by the authors. Licensee MDPI, Basel, Switzerland. This article is an open access article distributed under the terms and conditions of the Creative Commons Attribution (CC BY) license (https:// creativecommons.org/licenses/by/ $4.0 /)$.

\begin{abstract}
To study the reasons of the low academic performance of students in Spain, authorities must consider emotional dimensions, such as well-being, which directly affect their learning achievement. Furthermore, it would be interesting to compare Spanish students with students from Finland, which stand out in international rankings. We analyze how to promote students' well-being in Spain as a mechanism to enhance their academic achievement. Using data from PISA 2018, four indicators are used to measure well-being according to variables describing the students' context. By means of econometric techniques, interval multiobjective linear programming problems are formulated for Spain and Finland and solved through a new methodological scheme proposed in this paper, assuring the generation of possibly and necessarily efficient solutions in interval multiobjective linear programming. The purpose is to determine which aspects would allow the best possible well-being to be reached. We found several differences between the students achieving optimal compromise levels in each country, and we analyzed how the improvement of one indicator might affect the remaining aspects of well-being. Spanish students can further enhance their well-being compared to Finnish students. Furthermore, the lowest improvement rate is associated with the bullying index, especially in Finland, highlighting the need to promote anti-bullying measures.
\end{abstract}

Keywords: multiobjective optimization; econometric analysis; students' academic performance; students' satisfaction

\section{Introduction}

The educational definition of academic achievement has been evolving towards a more complete concept. Currently, the focus of interest is not only on students' grades in different subjects. Other aspects of their daily life, such as social skills, emotions and aspects of their well-being, are also being considered to quantify students' achievements, owing to the fact that academic performance is influenced by emotional factors [1-3]. In fact, it has been demonstrated that programs aimed at improving students' well-being are associated with better academic outcomes [4]. In Northern European countries, where students are very successful academically, educational policies are designed considering socio-emotional learning and students' comprehensive development, which again supports the notion that academic performance does not exclusively depend on grades $[5,6]$.

Therefore, governments are more aware of the fact that social determinants of young people's health and well-being really have a great impact on their academic success. They are currently showing greater interest in learning how to work with students to understand well-being from the their perspective, and how to take actions to enhance it [7]. Note that analyzing and promoting students' well-being would not only have a positive effect on education but also on the economy of any country, since education also contributes to economic growth [8]. In this context, the main purpose of this paper is to study how to promote the well-being of adolescents from a multicriteria decision-making perspective. We analyze several aspects quantifying the well-being of students to determine if the 
levels attained could be simultaneously improved to achieve the best possible ("optimal") well-being situation, as a way to promote their academic performance.

In order to enhance students' well-being, first, it is essential to know how to measure it and which factors affect it. It is accepted that well-being is a concept that comprises several aspects related to the quality of life of individuals and their satisfaction with life in general, but there is no widely accepted common definition [9]. Broadly speaking, students' well-being is characterised as a multidimensional concept [10] covering cognitive, physical, social, and psychological aspects [6]. In our proposal, we evaluate the well-being by means of four indexes included in the last two PISA reports $[6,11]$ : index of positive feelings, index of motivation at school, index of sense of belonging and index of bullying. However, these well-being indexes are influenced by the characteristics of students' teaching-learning context, and this information must be conveniently considered to perform a complete study of the situation. Specifically, we consider the sociodemographic data of students and information about their learning context, such as the support they perceive from teachers, use of ICTs, and disciplinary climate at school.

In our study, we intend to investigate how the best possible level of students' wellbeing can be attained through the simultaneous optimization of positive feelings, motivation, sense of belonging and bullying indexes, defined as functions of the variables describing characteristics and factors of the teaching-learning environment. For this purpose, we performed an econometric analysis of the data, in order to regress the indexes representing well-being according to these explanatory variables and to find the significant dependencies existing among them.

Based on the PISA 2018 dataset [6], we focused on Spanish and Finnish students to assess the differences existing between these two samples in terms of well-being. Furthermore, we aimed to gain an insight into the improvement strategies to be followed in each country to promote their students' situation. Note that, while Finland is usually ranked in the top positions of international rankings evaluating the academic performance of students, Spanish youth have shown low educational performances in comparison with students from other European countries [6,11]. Therefore, there is a need to study the possible causes of the situation of students in Spain, especially from a multidimensional perspective. Our work will propose actions to promote students' well-being in Spain-and, consequently, their academic achievement-especially in comparison with Finland.

The econometric study initially performed using the Spanish and the Finnish samples reveals certain opposite effects that several of the explanatory variables considered have on the well-being indexes, in the sense that one index is shown to be positively affected by a variable, which in turn has a negative impact on some of the other indexes. In terms of optimization, this means that the indexes are in conflict, which supports the analysis of this situation using a multiobjective programming approach. Therefore, we built a multiobjective optimization problem for each country in order to inspect the trade-offs and compromises existing among these students' well-being indexes in Spain and Finland, and to gain an insight into how to reach optimal balanced well-being among students in both countries. As shown herein, the econometric regression analysis provides the basis to define the objective functions and constraints of the two models.

Instead of using a deterministic optimization approach, interval multiobjective optimization approaches were applied with the purpose of capturing all the information provided by the data and analyzing student well-being in the most realistic manner. Unlike other techniques handling uncertainty, such as stochastic and fuzzy multiobjective programming [12-17], interval multiobjective programming does not assume that the coefficients of the problem definition follow statistical distributions. Instead, the uncertainty surrounding the problem is considered by using intervals to define some (or all) of the coefficients of the problem's functions [18]. From a theoretical point of view, in this paper, we also propose a general approach based on scalarizing functions to obtain necessarily and possibly efficient solutions to interval multiobjective linear programming problems. 
To find the profile of the Spanish and Finnish students reaching a compromise in optimal values for the indexes, we solved the Spanish and Finnish models with the proposed approach using some preferences about the ideal desirable levels of the well-being indicators. Specifically, for each country, we used the worst and best possible ideal scenarios for the indexes (i.e., individual optimal index values obtained with the lower and upper bounds of the coefficients, respectively [19]). This enabled us to obtain efficient solutions under different ideal situations.

By applying a combination of econometric and multiobjective optimization techniques, we obtained information regarding the values of the explanatory variables that should be attained to reach an optimal balance among the positive feelings, motivation, sense of belonging and bullying indexes (objective functions). Besides identifying the types of tradeoffs existing between the four indexes (i.e., sacrifices in some of the objectives to reach a gain in any of the others), our approach makes it possible to determine the effects that small changes in the explanatory variables may have on the levels achieved by each index. This piece of information may be very valuable for educational policy makers, since they could define policies to promote the students' well-being with some knowledge of the possible impacts of such policies in the future. Previously, some papers have shown the potential of this combined methodology to analyze different socioeconomic situations (see e.g., $[20,21]$ ), including the use of different multiobjective optimization approaches to solve the problems obtained. For example, in [20], the problem was solved by means of goal programming, while in [21], an interval multiobjective programming approach was applied. Nevertheless, to the best of our knowledge, none of them uses interval multiobjective programming to compare the well-being situations of students in two different countries, as in our study.

In summary, the main contributions of this paper are, on the one hand, the evaluation of the well-being levels of Spanish and Finnish students. For this purpose, an econometric analysis was first carried out using data from the PISA 2018 report on Spanish and Finnish students, in which we evaluated the relation among the four indexes considered and a set of explanatory variables. Second, according to the information obtained, interval multiobjective optimization models were constructed for Spain and Finland, which were solved under different scenarios to compare the profiles of the ideal students achieving a compromise among the four indexes in both countries. On the other hand, in the field of interval multiobjective linear programming, theoretical results were also proposed to generate necessarily and possibly efficient solutions based on a scalarizing function approach.

The rest of the paper is organized as follows. Section 2 presents the data considered and the econometric study performed, based on which we built the two interval multiobjective optimization models to analyze the well-being of students in Spain and Finland. In Section 3, we describe the theoretical approach suggested for interval multiobjective linear programming models. Section 4 provides the results obtained when solving the Spanish and Finnish models using the theoretical approach proposed. Finally, conclusions and future lines of research are drawn in Section 5, where we also discuss some interesting findings.

\section{Econometric Analysis for Building a Multiobjective Interval Programming Model}

This section starts by presenting the observational data and variables used in our study for Spain and Finland (Section 2.1). Next, we describe the regression analysis performed for both countries (Section 2.2), in order to detect the dependencies of students' well-being indexes with respect to the selected explanatory variables, and to identify the correlations existing among them. Finally, based on the previous analysis, we explain the formulation of two interval multiobjective linear programming models, one for each country, aimed at studying the conflicting relation among the four indexes (Section 2.3).

\subsection{Observational Data Used in Our Study}

Here, we describe the observational data considered, the independent variables (decision variables) and the dependent variables (objective functions). 
The dataset used for our analysis was derived from PISA 2018 [6]. PISA is the Programme for International Student Assessment of the Organization for Economic Cooperation and Development (OECD), which is designed to examine 15-year-old students' knowledge and abilities in reading, mathematics and science (http:/ / www.oecd.org/pisa/, accessed on 20 June 2021). Besides data regarding their knowledge and skills in the three subjects, it also provides a wide range of information about students' personal features. In 2018, approximately, 612,000 15-year-old students participated in this assessment, in about 80 countries.

In the PISA assessment, students had to complete several tests, consisting of multiplechoice questions and open questions requiring them to write their own responses, concerning the three subjects (science, mathematics and reading). PISA also covers general or cross-cutting skill measures, such as collaborative problem solving, with special emphasis on functional skills that students have acquired as the end of compulsory schooling approaches. In addition, pupils had to answer a background questionnaire that sought information about their sociodemographic features, their homes and school learning experiences.

In the case of Spain, 35,943 students from 1089 schools participated in the assessment in 2018. However, our analysis only considered non-repeater students (given that repeaters will be in lower grades) and students enrolled in public and semi-private schools (private schools are not representative). Considering the missing data, the sample used finally consisted of 21,572 Spanish students. For Finland, 5649 students from 214 schools were assessed in 2018 but, after reducing the sample in the same way as the Spanish case (only non-repeater students and those from semi-private and public schools), only 3806 Finnish students in the sample were considered (once we eliminated the missing data).

Since 2015, in some countries (such as Spain and Finland), students also complete two more questionnaires in PISA, one related to their abilities with Information and Communication Technologies (ICTs), and another one related to their well-being as students. Based on the answers to the latter questionnaire, several indexes were built in PISA (using a reduced sample of the data) to quantify the students' well-being and four of these indicators were used in this study: an index to quantify positive feelings of students, a motivation index, an index to measure the sense of belonging to the school, and an index of bullying at school. Note that the higher the values of the first three indexes (positive feelings, motivation and sense of belonging), the better the well-being of a student is, while it is preferred to achieve the lowest possible level for the bullying index. In our study, we replicated these four indexes through factor analysis using the Spanish and Finnish samples considered.

Table 1 depicts the notation and a detailed description of the four well-being indexes used (denoted by $y_{j}$, for $j=1, \ldots, 4$ ), as well as the explanatory variables we considered for students' teaching-learning environment (denoted by $x_{i}$, for $i=1, \ldots, 8$ ).

Table 2 shows the descriptive statistics of these variables (mean, standard deviation, minimum and maximum values) for Spain and Finland. Additionally, to provide information about the variability of the data used, we show a graphical description of the variables in Figures 1 and 2, which depict box-plots of the variables' values for the Spanish and Finnish samples, respectively.

In relation to teacher support, it must be noted that high values (or low values, respectively) for this variable mean that students perceived that their teacher supported them less frequently (or more frequently, respectively). Therefore, ideally, this variable should obtain the lowest possible values. 
Table 1. Well-being indexes and explanatory variables.

\begin{tabular}{|c|c|c|c|}
\hline & Notation & Description & Type \\
\hline Well-being indexes & & Built by combining the answers to these questions: & \\
\hline Positive feelings & $y_{1}$ & How frequently ("never", "rarely", "sometimes", "always") do you feel happy, joyful and cheerful? & Continuous \\
\hline Motivation & $y_{2}$ & $\begin{array}{l}\text { To which extent do you agree or disagree ("strongly disagree", "disagree", "agree", "strongly agree") with the following } \\
\text { statements? "I find satisfaction in working as hard as I can"; "Once I start a task, I persist until it is finished"; and "Part of } \\
\text { the enjoyment I get from doing things is when I improve on my past performance" }\end{array}$ & Continuous \\
\hline Sense of belonging & $y_{3}$ & $\begin{array}{l}\text { To which extent do you agree or disagree ("strongly disagree", "disagree", "agree", "strongly agree") with the following } \\
\text { statements? "I feel like an outsider (or left out of things) at school"; "I make friends easily at school"; "I feel like I belong at } \\
\text { school"; "I feel awkward and out of place in my school"; "Other students seem to like me"; and "I feel lonely at school" }\end{array}$ & Continuous \\
\hline Bullying & $y_{4}$ & $\begin{array}{l}\text { How often ("never or almost never", "a few times a year", "a few times a month", "once a week or more") have you had the } \\
\text { following experiences in school? "Other students left me out of things on purpose"; "Other students made fun of me"; and "I } \\
\text { was threatened by other students" }\end{array}$ & Continuous \\
\hline \multicolumn{4}{|l|}{$\begin{array}{l}\text { Explanatory vari- } \\
\text { ables }\end{array}$} \\
\hline $\begin{array}{l}\text { Socioeconomic in- } \\
\text { dex }\end{array}$ & $x_{1}$ & Index of economic, social and cultural status & Continuous \\
\hline School type & $x_{2}$ & Type of school (semi-private 1-public 0 ) & Binary \\
\hline Gender & $x_{3}$ & Male or female (girl 1-boy 0) & Binary \\
\hline $\begin{array}{l}\text { Internet outside } \\
\text { school }\end{array}$ & $x_{4}$ & Amount of time (hours) students spend connected to the Internet during a typical week & Continuous \\
\hline $\begin{array}{l}\text { Starting age for us- } \\
\text { ing digital devices }\end{array}$ & $x_{5}$ & How old were you when you first used a digital device? & Continuous \\
\hline Teacher support & $x_{6}$ & $\begin{array}{l}\text { Index built by combining the answers to the following questions: How often ("every lesson", "most lessons", "some } \\
\text { lessons", "never or hardly ever") the following things happen in your language-of-instruction lessons? "The teacher shows an } \\
\text { interest in every student's learning"; "The teacher gives extra help when students need it"; "The teacher helps students with } \\
\text { their learning"; and "The teacher continues teaching until the students understand" }\end{array}$ & Continuous \\
\hline $\begin{array}{l}\text { Disciplinary cli- } \\
\text { mate }\end{array}$ & $x_{7}$ & $\begin{array}{l}\text { Index built by combining the answers to the following questions: How often ("every lesson", "most lessons", "some } \\
\text { lessons", "never or hardly ever") the following things happen in your language-of-instruction lessons? "Students don't listen } \\
\text { to what the teacher says"; "There is noise and disorder"; "The teacher has to wait a long time for students to quiet down"; } \\
\text { "Students cannot work well"; and "Students don't start working for a long time after the lesson begins" }\end{array}$ & Continuous \\
\hline Foreign language & $x_{8}$ & Number of class periods per week in foreign language & Continuous \\
\hline
\end{tabular}

Table 2. Descriptive statistics of the variables.

\begin{tabular}{|c|c|c|c|c|c|c|c|c|c|}
\hline & & \multicolumn{4}{|c|}{ Spanish Sample } & \multicolumn{4}{|c|}{ Finnish Sample } \\
\hline & & Mean & Std.Dev. & Min & $\operatorname{Max}$ & Mean & Std.Dev. & Min & Max \\
\hline \multicolumn{10}{|l|}{ Well-being indexes } \\
\hline Positive feelings & $y_{1}$ & 0.0370 & 0.8795 & -4.0655 & 0.9016 & 0.0319 & 0.8470 & -3.5534 & 1.2458 \\
\hline Motivation & $y_{2}$ & 0.0633 & 0.7944 & -3.3026 & 1.2486 & 0.0477 & 0.8035 & -2.6023 & 1.7535 \\
\hline Sense of belonging & $y_{3}$ & -0.0150 & 0.8740 & -2.8899 & 1.2096 & 0.0084 & 0.8714 & -2.6099 & 1.7008 \\
\hline Bullying & $y_{4}$ & -0.0801 & 0.7831 & -0.4818 & 5.4689 & -0.0529 & 0.8256 & -0.5496 & 5.1960 \\
\hline \multicolumn{10}{|l|}{ Explanatory variables } \\
\hline Socioeconomic index & $x_{1}$ & 0.0338 & 0.9466 & -4.3160 & 3.7171 & 0.3151 & 0.7591 & -2.8210 & 2.3690 \\
\hline School type & $x_{2}$ & 0.2955 & 0.4563 & 0.0000 & 1.0000 & 0.0355 & 0.1850 & 0.0000 & 1.0000 \\
\hline Gender & $x_{3}$ & 0.5445 & 0.4980 & 0.0000 & 1.0000 & 0.5478 & 0.4977 & 0.0000 & 1.0000 \\
\hline $\begin{array}{l}\text { Internet } \quad \text { outside } \\
\text { school }\end{array}$ & $x_{4}$ & 3.6811 & 2.0533 & 0.0000 & 7.0000 & 3.5339 & 1.8695 & 0.0000 & 7.0000 \\
\hline $\begin{array}{l}\text { Starting age for us- } \\
\text { ing digital devices }\end{array}$ & $x_{5}$ & 7.5441 & 2.7196 & 4.5000 & 14.5000 & 6.0820 & 2.0357 & 4.5000 & 14.5000 \\
\hline Teacher support & $x_{6}$ & 0.0194 & 0.9231 & -0.9723 & 2.4550 & -0.0337 & 0.9124 & -0.9294 & 2.9460 \\
\hline Disciplinary climate & $x_{7}$ & 0.0349 & 0.9653 & -2.1020 & 1.4652 & 0.0106 & 0.9611 & -2.4839 & 1.4610 \\
\hline Foreign language & $x_{8}$ & 4.2554 & 1.3111 & 3.0000 & 7.0000 & 4.7812 & 1.1922 & 3.0000 & 7.0000 \\
\hline
\end{tabular}




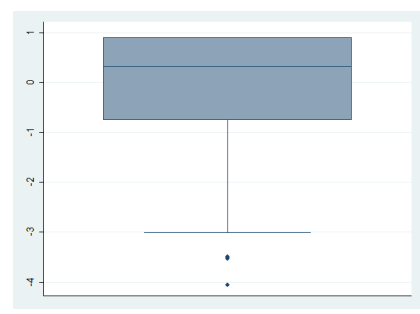

(a) Positive feelings

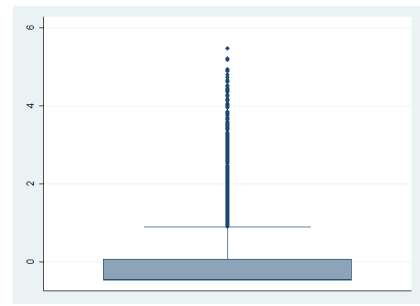

(d) Bullying

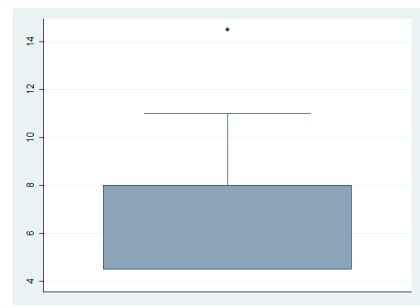

(g) Starting age for using digital devices

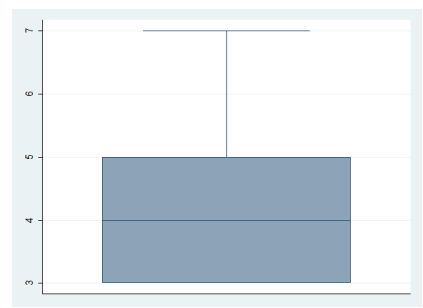

(j) Foreign language

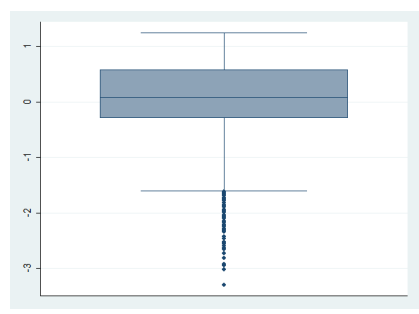

(b) Motivation

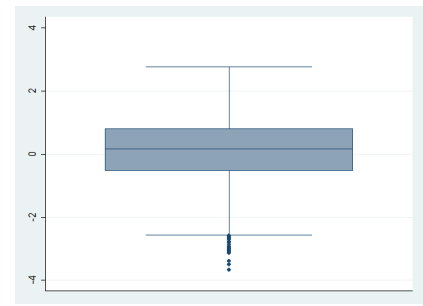

(e) Socioeconomic index

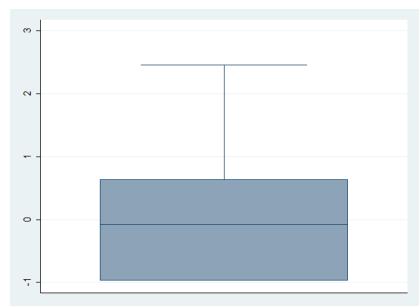

(h) Teacher support

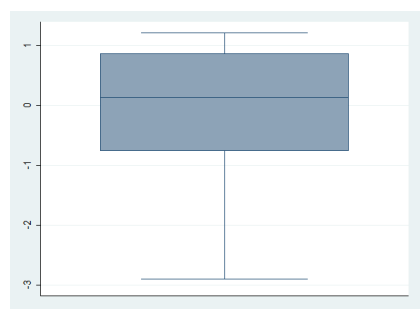

(c) Sense of belonging

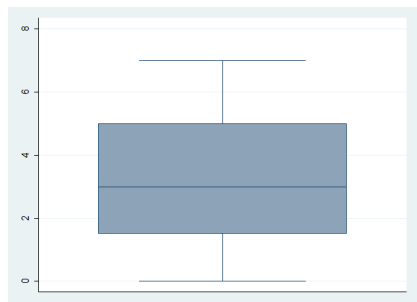

(f) Internet outside school

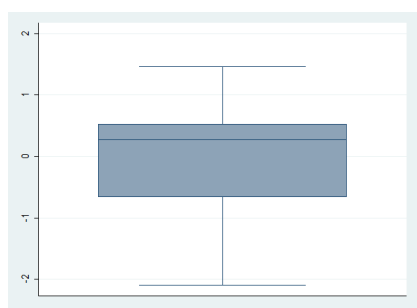

(i) Disciplinary climate

Figure 1. Box-plots of the variables for the Spanish sample.

According to the observational data, in Spain, 29.5\% of the students are enrolled in semi-private schools, whereas $70.5 \%$ of them are enrolled in public schools. In the case of Finland, the semi-private school students only represent 3.6\% of the sample, while $96.4 \%$ of the pupils attend a public school, which implies that there are hardly any semi-private schools in Finland.

Concerning the proportion of students by gender, we can see that girls and boys are equally represented in both countries. On average, Spanish students access the Internet outside school $3.68 \mathrm{~h}$ per day, and they started using digital devices at the age of seven. In Finland, on average, students use the Internet for $3.53 \mathrm{~h}$ per day outside school and had their first contact with a digital device when they were six years old (earlier than the Spanish pupils). Regarding the disciplinary climate, there are no significant differences, on average, between both countries. Finally, Spanish students spend a mean of 4.25 class periods studying in a foreign language at school, while Finnish students spend 4.78 periods on the same task. 


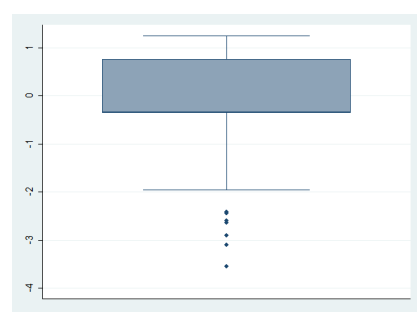

(a) Positive feelings

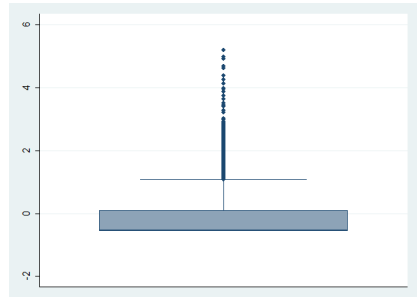

(d) Bullying

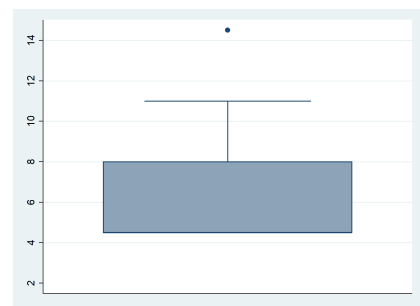

(g) Starting age for using digital devices

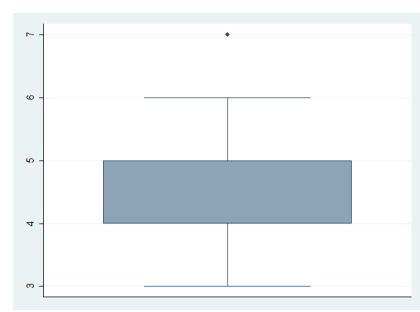

(j) Foreign language

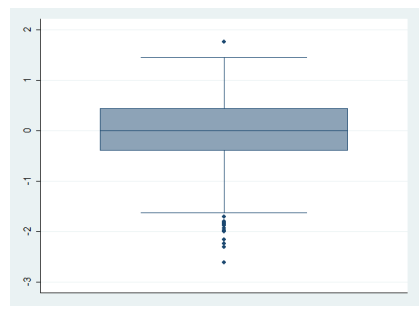

(b) Motivation

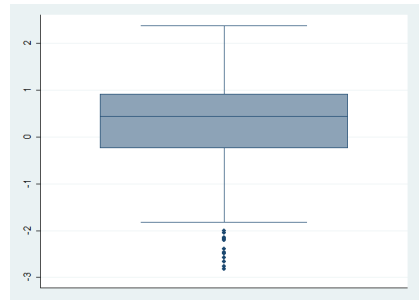

(e) Socioeconomic index

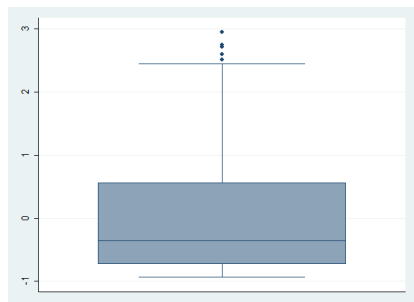

(h) Teacher support

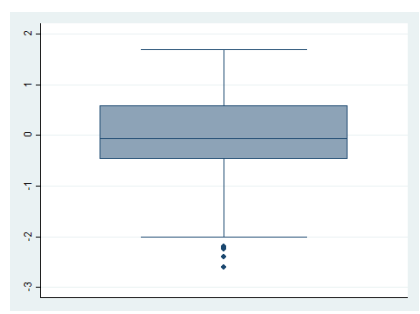

(c) Sense of belonging

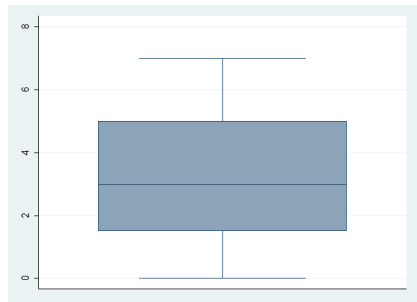

(f) Internet outside school

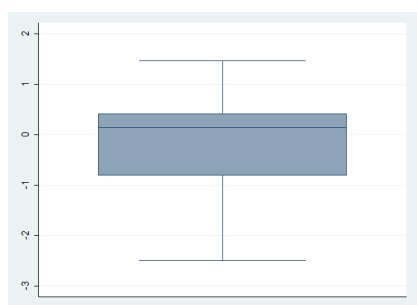

(i) Disciplinary climate

Figure 2. Box-plots of the variables for the Finnish sample.

\subsection{Regression Analysis}

We can approximate the level of well-being of each student through the regression of the four indexes (positive feelings, motivation, sense of belonging and bullying) with respect to the explanatory variables previously defined in Table 1 . If students are denoted by $s$ (with $s=1, \ldots, n$ (sample size)), the well-being indexes can be represented by the following set of equations:

$$
y_{j}(s)=\alpha^{j}+\beta_{1}^{j} x_{1}(s)+\beta_{2}^{j} x_{2}(s)+\cdots+\beta_{8}^{j} x_{8}(s)+\varepsilon^{j}(s), \quad j=1,2,3,4,
$$

where $y_{j}(s)$ is the estimated value of index $j$ for student $s ; x_{1}(s), x_{2}(s), \ldots, x_{8}(s)$ are the explanatory variable values for student $s ; \beta^{j}=\left(\beta_{1}^{j}, \ldots, \beta_{8}^{j}\right)^{T}$ is formed by the regression coefficients for the index $j ; \alpha^{j}$ is the constant term (intercept); and $\varepsilon^{j}(s)$ is an error term representing random and unobservable factors affecting the index $j$ for student $s$, which is assumed to be normally distributed. The regression coefficients were predicted using the Ordinary Least Squares (OLS) estimator, the idea of which is to minimize the so-called statistical noise as much as possible. The lower and upper bounds of the confidence intervals obtained at $95 \%$ for the estimated coefficients (significant at 10\%, 5\%, and 1\%) are 
given in Table 3 for Spain and in Table 4 for Finland. Note that the coefficients which were not significant are reported as 0 .

Table 3. Lower and upper bounds of the $95 \%$ confidence intervals for the regression coefficients for the Spanish sample.

\begin{tabular}{|c|c|c|c|c|c|c|c|c|c|}
\hline \multirow{2}{*}{ Explanatory Variables } & & \multicolumn{2}{|c|}{ Positive Feelings } & \multicolumn{2}{|c|}{ Motivation } & \multicolumn{2}{|c|}{ Sense of Belonging } & \multicolumn{2}{|c|}{ Bullying } \\
\hline & & Lower & Upper & Lower & Upper & Lower & Upper & Lower & Upper \\
\hline Socioeconomic index & $x_{1}$ & 0.0006 & 0.0554 & 0.0087 & 0.0603 & 0.0159 & 0.0661 & 0 & 0 \\
\hline School type & $x_{2}$ & 0 & 0 & 0 & 0 & 0.0395 & 0.1508 & 0 & 0 \\
\hline Gender & $x_{3}$ & -0.0980 & -0.0138 & 0.1274 & 0.2164 & -0.1006 & -0.0202 & -0.1707 & -0.0781 \\
\hline $\begin{array}{l}\text { Internet } \\
\text { school }\end{array}$ & $x_{4}$ & 0 & 0 & -0.0413 & -0.0209 & 0.0117 & 0.0341 & -0.0009 & 0.0250 \\
\hline $\begin{array}{l}\text { Starting age for us- } \\
\text { ing digital devices }\end{array}$ & $x_{5}$ & 0.0013 & 0.0160 & 0.0083 & 0.0218 & 0 & 0 & 0 & 0 \\
\hline Teacher support & $x_{6}$ & -0.1131 & -0.0614 & -0.1622 & -0.1111 & -0.1408 & -0.0803 & 0.0370 & 0.0843 \\
\hline Disciplinary climate & $x_{7}$ & 0.0284 & 0.0835 & 0.0084 & 0.0500 & 0.0367 & 0.0876 & -0.1278 & -0.0767 \\
\hline Foreign language & $x_{8}$ & 0 & 0 & 0.0087 & 0.0429 & 0 & 0 & 0 & 0 \\
\hline Constant & $\alpha$ & -0.0903 & 0.1106 & -0.2298 & -0.0383 & -0.2944 & -0.0391 & -0.1050 & 0.1258 \\
\hline Observations & $N$ & 12169 & 12169 & 12169 & 12169 & 12169 & 12169 & 12169 & 12169 \\
\hline $\mathrm{R}$-squared & $R^{2}$ & 0.0181 & 0.0181 & 0.0555 & 0.0555 & 0.0319 & 0.0319 & 0.0329 & 0.0329 \\
\hline
\end{tabular}

Table 4. Lower and upper bounds of the $95 \%$ confidence intervals for the regression coefficients for the Finnish sample.

\begin{tabular}{|c|c|c|c|c|c|c|c|c|c|}
\hline \multirow{2}{*}{ Explanatory Variables } & & \multicolumn{2}{|c|}{ Positive Feelings } & \multicolumn{2}{|c|}{ Motivation } & \multicolumn{2}{|c|}{ Sense of Belonging } & \multicolumn{2}{|c|}{ Bullying } \\
\hline & & Lower & Upper & Lower & Upper & Lower & Upper & Lower & Upper \\
\hline Socioeconomic index & $x_{1}$ & 0.0773 & 0.1535 & 0.1384 & 0.2057 & 0.0267 & 0.1159 & 0 & 0 \\
\hline School type & $x_{2}$ & 0 & 0 & 0 & 0 & -0.3630 & -0.0371 & 0 & 0 \\
\hline Gender & $x_{3}$ & 0 & 0 & 0.0576 & 0.1714 & -0.2973 & -0.1652 & -0.1888 & -0.0663 \\
\hline $\begin{array}{l}\text { Internet } \quad \text { outside } \\
\text { school }\end{array}$ & $x_{4}$ & -0.0879 & -0.0576 & -0.1042 & -0.0709 & -0.0507 & -0.0143 & 0.0230 & 0.0604 \\
\hline $\begin{array}{l}\text { Starting age for us- } \\
\text { ing digital devices }\end{array}$ & $x_{5}$ & 0 & 0 & 0 & 0 & 0 & 0 & 0 & 0 \\
\hline Teacher support & $x_{6}$ & -0.1640 & -0.0901 & -0.1521 & -0.0788 & -0.1354 & -0.0565 & 0.0762 & 0.1575 \\
\hline Disciplinary climate & $x_{7}$ & 0.0003 & 0.0628 & 0.0003 & 0.0656 & 0.0318 & 0.0998 & -0.1479 & -0.0841 \\
\hline Foreign language & $x_{8}$ & 0 & 0 & 0.0002 & 0.0513 & 0 & 0 & 0 & 0 \\
\hline Constant & $\alpha$ & 0.1825 & 0.5121 & -0.0424 & 0.2803 & 0.0142 & 0.3658 & -0.3937 & -0.0568 \\
\hline Observations & $N$ & 3084 & 3084 & 3084 & 3084 & 3084 & 3084 & 3084 & 3084 \\
\hline $\mathrm{R}$-squared & $R^{2}$ & 0.0697 & 0.0697 & 0.1107 & 0.1107 & 0.0515 & 0.0515 & 0.0586 & 0.0586 \\
\hline
\end{tabular}

According to the results obtained for both countries, we can see that the socioeconomic index positively affects the index of positive feelings. Additionally, teacher support and disciplinary climate also have a favorable effect on the students' positive feelings for the two cases (let us remark that the lower the teacher support variable value, the more support the students perceive from the teacher). However, we can find some differences between the Spanish and Finnish samples in some of the other variables. In Spain, boys are shown to have good levels of positive feelings, and children who start using digital devices later report high levels of positive feelings. However, these two variables were not significant for the positive feelings index in the case of Finland. Furthermore, our findings suggest that Finnish students who spend more time using the Internet outside school have lower values of positive feelings, while this relation was not detected as significant for Spain.

Focusing on the motivation index, the conclusions are very similar for both countries. As expected, our data show that socioeconomically advantaged students are more motivated than students coming from a lower status family. In line with other studies in the field [22], our analysis also suggests that both Spanish and Finnish girls report more motivation to learn than boys. The number of hours students are connected to the Internet outside school negatively affects motivation in both countries. This fact is also found, e.g., in [23]. In addition, for both cases, we see that students who are supported by teachers are likely to be more motivated than students perceiving less support [24]. Indeed, studying in a highly disciplinary environment is positively correlated with motivation (as stated by other authors [25]). Finally, we can observe that being taught in a foreign language improves the student's motivation in both countries. 
Concerning the sense of belonging to the school, as in other studies [6], we found that boys of both nationalities show a higher sense of belonging than girls, and this feeling is also observed to be higher in socioeconomically advantaged students. In line with other studies [26], our analysis shows that students from Spain and Finland with a higher perception of teacher support report satisfactory levels for the sense of belonging. Additionally, in a more disciplinary climate, students are expected to have a strong feeling of belonging than in a less disciplinary environment, in accordance with [11]. However, there are variables showing an opposite relation with this well-being index for Spain and Finland. On the one hand, the school type is positively correlated with the sense of belonging in the case of Spain, that is, the estimators reveal that Spanish students enrolled in semi-private schools are likely to feel they belong to school more than those studying in public schools. On the contrary, the opposite relation is observed in Finland: our results suggest that a higher sense of belonging corresponds to public school students in Finland. This may be explained by the low percentage of Finnish students enrolled in semi-private schools in comparison to Spain (3.6\% for the former versus $29.5 \%$ for the latter, as shown in Section 2.1).

In relation to the bullying index, the findings are similar for both countries. Our results indicate that boys are more likely to be victims of bullying than girls, in line with [27]. Students who spend more hours using the Internet outside school seem to suffer a higher rate of bullying. This finding is supported by the conclusions raised in [28], which demonstrated that the more time spent on social networks, the greater the risk of suffering bullying. On the other hand, following [29], we concluded that students who are supported by teachers are less likely to be bullied, and that the disciplinary climate variable is negatively correlated with the bullying index, which means that studying in a stricter environment is associated with fewer pupils being bullied.

Finally, this regression analysis allowed us to detect a certain degree of conflict between the four well-being indexes. Ideally, the positive feeling, the motivation and the sense of belonging indexes should be as high as possible (i.e., they should be maximized), while bullying is meant to achieve the lowest level (i.e., they should be minimized). Based on our study, in relation to gender, our findings suggest that girls are more motivated and face less bullying than boys, but they seem to achieve lower levels for the sense of belonging to the school than boys and, only for Spain, girls also report less positive feelings than boys. This reveals that there is a clear conflict among the four indexes since, at least considering girls and boys, when the motivation and bullying indexes attain good levels, reports of a sense of belonging and positive feelings (only for the Spanish case) attain lower values.

In addition, in the Spanish case, we can also observe that motivation, sense of belonging and bullying are conflicting depending on the time of Internet use outside school. Note that the more time students spend on the Internet, the less motivated they are expected to be, the higher the sense of belonging they are likely to express and the more bullying they might suffer. This means that, when using the Internet outside school for long periods of time, motivation and bullying attain lower values, but the positive feelings index attains better levels.

This conflicting relation among the four indicators encouraged us to apply multiobjective optimization techniques to this problem. Studying this phenomenon from the multiobjective optimization perspective enabled us to gain further insight into how to achieve a compromise between the four well-being indicators, i.e., how to reach optimal values for the four variables at the same time as a way to enhance student satisfaction.

\subsection{Interval Multiobjective Linear Programming Models for Spain and Finland}

In this section, we provide details about the two multiobjective optimization models built to analyze the well-being of students in Spain and Finland. The main purpose was to study how the four indicators (positive feelings, motivation, sense of belonging and bullying) could be improved simultaneously, according to the particularities of each country. Given that we observed a conflicting relation among the indicators, information 
about what is feasible and what is not is required to design specific educational policies and to foresee their impact on students' lives. Furthermore, if a Spanish or Finnish policymaker wants to make a suitable decision to enhance the achievement levels of the indicators, they need to research which sacrifices would be needed among them to attain the most desired well-being situation. In fact, information about the profile of students with a balance among the four indexes would allow them to design policies and protocols in each country whilst being aware of the possible impacts of the measures in this regard. This multiobjective optimization analysis would also permit the comparison of the situations and needs of students in both countries.

On the basis of the data detailed in Section 2.1 and the regressions indicated in Section 2.2, we formulated linear models of interval multiobjective programming. In general, interval multiobjective programming approaches are very useful to study real-world problems taking into account the uncertainty of the phenomenon under scrutiny $[18,30]$. Instead of using values fixed a priori (mean values in many cases) to define all coefficients and parameters, these models assume that the information required is seldom incomplete and subject to uncertainty. Thus, they are formulated considering that the coefficients of the model (either in the objective functions, in the constraints and/or in any other parameter) are presumed to lie within a range of variation. In practice, interval multiobjective programming models have many possible formulations (see e.g., [31,32] and references therein). The scope of this paper is focused on multiobjective linear programming problems with interval objective functions, that is, models with objective functions formulated with intervals of values as coefficients. We consider an interval multiobjective linear programming problem (abbreviated as interval MOLP problem) defined as follows:

$$
\begin{array}{lll}
\operatorname{maximize} & Z_{k}(\mathbf{x})=\sum_{j=1}^{n}\left[c_{k j}^{L}, c_{k j}^{U}\right] x_{j}, & k=1, \ldots, p, \\
\text { subject to } & \sum_{j=1}^{n} a_{i j} x_{j} \leq b_{i}, & i=1, \ldots, m, \\
& x_{j} \geq 0, & j=1, \ldots, n,
\end{array}
$$

where $\mathbf{x}=\left(x_{1}, \ldots, x_{n}\right)^{T} \in \mathbb{R}^{n}$ is the vector of $n$ decision variables and $Z_{k}: \mathbb{R}^{n} \rightarrow R$ $(k=1, \ldots, p)$ are the $p$ conflicting interval objective functions to be maximized (with $p \geq 2$ ). In this formulation, the feasible region is determined by $m$ linear constraints and the non-negativity of the variables:

$$
X=\left\{\mathbf{x} \in \mathbb{R}^{n} \text { such that } \sum_{j=1}^{n} a_{i j} x_{j} \leq b_{i}, i=1, \ldots, m \text {, and } x_{j} \geq 0, j=1, \ldots, n\right\} .
$$

It seems natural to combine interval multiobjective programming techniques with econometric approaches to gain further insight into the problem being studied, since the combination of these methodologies will enable us to consider distinct scenarios that otherwise could be overlooked. Specifically, econometric models manage uncertainty when estimating the parameters showing the statistical relationships among the variables, so the information obtained about the estimators can be used to formulate interval multiobjective programming models. In particular, we can consider the confidence intervals for the regression coefficients of the predictors-reflecting the desired percentage $p$ of the observational data - to build linear interval functions and use them to formulate an interval MOLP problem.

This is the basic idea underlying the building process we followed to formulate the two models described in the following, one for Spain and one for Finland, which are aimed at studying how the well-being of students could be improved in each country. In these problems, we considered linear interval objective functions to represent the four well-being indexes. Table 5 depicts the formulations obtained for these functions using the confidence intervals (at 95\%) of the regression coefficients of the four indexes (which were previously provided in Tables 3 and 4). 
Table 5. Linear interval objective functions for Spain and Finland.

\begin{tabular}{lll}
\hline Well-Being Indexes & Max/Min & Formulation \\
\hline Spain & & \\
\hline Positive feelings & Max & $Z_{1}=[0.0006,0.0554] \cdot x_{1}+\cdots+[0.0284,0.0835] \cdot x_{7}+[-0.0903,0.1106]$ \\
Motivation & Max & $Z_{2}=[0.0087,0.0603] \cdot x_{1}+\cdots+[0.0087,0.0429] \cdot x_{8}+[-0.2298,-0.0383]$ \\
Sense of belonging & Max & $Z_{3}=[0.0159,0.0661] \cdot x_{1}+\cdots+[0.0367,0.0876] \cdot x_{7}+[-0.2944,-0.0391]$ \\
Bullying & Min & $Z_{4}=[-0.1707,-0.0781] \cdot x_{3}+\cdots+[-0.1278,-0.0767] \cdot x_{7}+[-0.1050,0.1258]$ \\
\hline Finland & & \\
\hline Positive feelings & Max & $Z_{1}=[0.0773,0.1535] \cdot x_{1}+\cdots+[0.0003,0.0628] \cdot x_{7}+[0.1825,0.5121]$ \\
Motivation & Max & $Z_{2}=[0.1384,0.2057] \cdot x_{1}+\cdots+[0.0002,0.0513] \cdot x_{8}+[-0.0424,0.2803]$ \\
Sense of belonging & Max & $Z_{3}=[0.0267,0.1159] \cdot x_{1}+\cdots+[0.0318,0.0998] \cdot x_{7}+[0.0142,0.3658]$ \\
Bullying & Min & $Z_{4}=[-0.1888,-0.0663] \cdot x_{3}+\cdots+[-0.1479,-0.0841] \cdot x_{7}+[-0.3937,-0.0568]$ \\
\hline
\end{tabular}

The feasible sets of the two interval MOLP problems have been built to assure that only meaningful and sufficiently realistic values of the decision variables (i.e., the explanatory variables) are possible. For this purpose, we considered bound constraints that were formulated using the confidence intervals of the variables showing a significant correlation in a linear regression analysis. In Table 6, we indicate which combinations of variables were found to be significantly dependent for both countries. In this table, we show the lower and upper bounds of the confidence intervals (at 95\%) for the slopes and the constant of the linear estimation of the variable in the dependent variable column with the ones in the independent variable column.

Table 6. Confidence intervals for the variables showing a statistically significant dependency (at 95\%) for Spain and Finland.

\begin{tabular}{|c|c|c|c|c|c|}
\hline \multirow{2}{*}{ Dependent Variable } & \multirow{2}{*}{ Independent Variable } & \multicolumn{2}{|c|}{ Slope } & \multicolumn{2}{|c|}{ Constant } \\
\hline & & Lower & Upper & Lower & Upper \\
\hline \multicolumn{6}{|l|}{ Spain } \\
\hline Internet outside school $\left(x_{4}\right)$ & $\begin{array}{l}\text { Socioeconomic index }\left(x_{1}\right) \\
\text { Gender }\left(x_{3}\right)\end{array}$ & $\begin{array}{l}-0.3070 \\
0.1443\end{array}$ & $\begin{array}{l}-0.1906 \\
0.3677\end{array}$ & 3.4583 & 3.6419 \\
\hline Starting age for using digital devices $\left(x_{5}\right)$ & $\begin{array}{l}\text { Socioeconomic index }\left(x_{1}\right) \\
\text { Gender }\left(x_{3}\right)\end{array}$ & $\begin{array}{l}-0.3852 \\
0.3944\end{array}$ & $\begin{array}{l}-0.2479 \\
0.6532\end{array}$ & 7.1713 & 7.3679 \\
\hline Foreign language outside school $\left(x_{8}\right)$ & $\begin{array}{l}\text { Socioeconomic index }\left(x_{1}\right) \\
\text { Gender }\left(x_{3}\right)\end{array}$ & $\begin{array}{l}0.0601 \\
0.0327\end{array}$ & $\begin{array}{l}0.1724 \\
0.1742\end{array}$ & 4.1200 & 4.2703 \\
\hline \multicolumn{6}{|l|}{ Finland } \\
\hline Starting age for using digital devices $\left(x_{5}\right)$ & $\begin{array}{l}\text { Socioeconomic index }\left(x_{1}\right) \\
\text { Gender }\left(x_{3}\right)\end{array}$ & $\begin{array}{l}-0.3564 \\
0.0092\end{array}$ & $\begin{array}{l}-0.1395 \\
0.3685\end{array}$ & 5.9299 & 6.1835 \\
\hline Foreign language outside school $\left(x_{8}\right)$ & $\begin{array}{l}\text { Socioeconomic index }\left(x_{1}\right) \\
\text { Gender }\left(x_{3}\right)\end{array}$ & $\begin{array}{l}0.0061 \\
0.0118\end{array}$ & $\begin{array}{l}0.1363 \\
0.1749\end{array}$ & 4.6244 & 4.7907 \\
\hline
\end{tabular}

For the sake of clarity, an example of dependency is now described to explain how the bound constraints are formulated to only guarantee solutions whose values for the correlated variables are within the confidence intervals. According to Table 6, in the Spanish case, a certain correlation was detected, for example, the duration of Internet use outside school $\left(x_{4}\right)$ with respect to the socioeconomic index $\left(x_{1}\right)$ and gender $\left(x_{3}\right)$, whose linear regression would be $x_{4}=\beta_{1} \cdot x_{1}+\beta_{3} \cdot x_{3}+\alpha$. The confidence intervals for these regression coefficients are (at 95\%): $\beta_{1} \in[-0.3070,-0.1906], \beta_{3} \in[0.1443,0.3677]$ and $\alpha \in[3.4583,3.6419]$ (see Table 6). This implies that, according to our data, the possible values for $x_{4}$ would be bounded as follows:

$$
-0.3070 \cdot x_{1}+0.1443 \cdot x_{3}+3.4583 \leq x_{4} \leq-0.1906 \cdot x_{1}+0.3677 \cdot x_{3}+3.6419,
$$

which means that the following two constraints are incorporated into the Spanish model to control the values taken by these three variables: 


$$
\begin{array}{ll}
\left(-0.3070 \cdot x_{1}+0.1443 \cdot x_{3}+3.4583\right)-x_{4} \leq 0 & (\mathrm{C} 1-\mathrm{S}) \\
x_{4}-\left(-0.1906 \cdot x_{1}+0.3677 \cdot x_{3}+3.6419\right) \leq 0 & (\mathrm{C} 2-\mathrm{S}) .
\end{array}
$$

According to Table 6, for both the Spanish and the Finnish cases, similar bound constraints were built to reflect the correlation of the starting age for using digital devices $\left(x_{5}\right)$ with the socioeconomic index $\left(x_{1}\right)$ and gender $\left(x_{3}\right)$, as well as the correlation of the number of classes of foreign language $\left(x_{8}\right)$ with the previous two variables $\left(x_{1}\right.$ and $\left.x_{3}\right)$. In addition, the Spanish and Finnish problems consider lower and upper bounds to limit the values attained by the variables (denoted as $l_{i}^{S}, l_{i}^{F}$ and $u_{i}^{S}, u_{i}^{F}$, respectively, with $i=1, \ldots, 8$ ), which were defined using the minimum and maximum values observed at each sample (which were given in Table 2).

As a result, taking into account the objective functions given in Table 5, the bound constraints built with the information in Table 6 and the lower and upper variable bounds, the interval MOLP problems formulated to simultaneously optimize the well-being indexes in Spain and Finland are as follows (we would like to clarify that the interval objective functions in problems (3) and (4) have a constant term defined by an interval, although this term has been omitted in the general formulation of an interval MOLP problem given in (2)). For the sake of clarity, it is worth noting that the constant term of the objective functions does not influence the optimization process, i.e., the same optimal solutions would be obtained with or without it, and only the optimal objective values would vary in the corresponding amount.

$$
\begin{aligned}
& \text { Spain maximize } Z_{1}=[0.0006,0.0554] \cdot x_{1}+\cdots+[-0.0903,0.1106] \\
& \text { maximize } \quad Z_{2}=[0.0087,0.0603] \cdot x_{1}+\cdots+[-0.2298,-0.0383] \\
& \text { maximize } \quad Z_{3}=[0.0159,0.0661] \cdot x_{1}+\cdots+[-0.29443,-0.0391] \\
& \text { minimize } \quad Z_{4}=[-0.1707,-0.0781] \cdot x_{3}+\cdots+[-0.1050,0.1258] \\
& \text { subject to } \quad\left(-0.3070 \cdot x_{1}+0.1443 \cdot x_{3}+3.4583\right)-x_{4} \leq 0, \quad(\mathrm{C} 1-\mathrm{S}) \\
& x_{4}-\left(-0.1906 \cdot x_{1}+0.3677 \cdot x_{3}+3.6419\right) \leq 0, \quad(\mathrm{C} 2-\mathrm{S}) \\
& \left(-0.3852 \cdot x_{1}+0.3944 \cdot x_{3}+7.1713\right)-x_{5} \leq 0, \quad(\mathrm{C} 3-\mathrm{S}) \\
& x_{5}-\left(0.2479 \cdot x_{1}+0.6532 \cdot x_{3}+7.3679\right) \leq 0, \quad(\mathrm{C} 4-\mathrm{S}) \\
& \left(0.0601 \cdot x_{1}+0.0327 \cdot x_{3}+4.1200\right)-x_{8} \leq 0, \quad(\mathrm{C} 5-\mathrm{S}) \\
& x_{8}-\left(0.1724 \cdot x_{1}+0.1742 \cdot x_{3}+4.2703\right) \leq 0, \quad(\mathrm{C} 6-\mathrm{S}) \\
& l_{i}^{S} \leq x_{i} \leq u_{i}^{S}, \quad i=1, \ldots, 8 \text {. } \\
& \text { Finland maximize } Z_{1}=[0.0773,0.1535] \cdot x_{1}+\cdots+[0.1825,0.5121] \\
& \operatorname{maximize} \quad Z_{2}=[0.1384,0.2057] \cdot x_{1}+\cdots+[-0.0424,0.2803] \\
& \text { maximize } \quad Z_{3}=[0.0267,0.1159] \cdot x_{1}+\cdots+[0.0142,0.3658] \\
& \text { minimize } \quad Z_{4}=[-0.1888,-0.0663] \cdot x_{3}+\cdots+[-0.3937,-0.0568] \\
& \text { subject to } \quad\left(-0.3564 \cdot x_{1}+0.0092 \cdot x_{3}+5.9299\right)-x_{5} \leq 0, \quad(\mathrm{C} 1-\mathrm{F}) \\
& x_{5}-\left(-0.1395 \cdot x_{1}+0.3685 \cdot x_{3}+6.1835\right) \leq 0, \quad(\mathrm{C} 2-\mathrm{F}) \\
& \left(0.0061 \cdot x_{1}+0.0118 \cdot x_{3}+4.6244\right)-x_{8} \leq 0, \quad(\mathrm{C} 3-\mathrm{F}) \\
& x_{8}-\left(0.1363 \cdot x_{1}+0.1749 \cdot x_{3}+0.7907\right) \leq 0, \quad(\mathrm{C} 4-\mathrm{F}) \\
& l_{i}^{F} \leq x_{i} \leq u_{i}^{F}, \quad i=1, \ldots, 8 .
\end{aligned}
$$

\section{Interval Multiobjective Linear Programming: A Novel Approach to Obtain Possibly Efficient Solutions}

As previously mentioned, interval multiobjective programming approaches are specially designed to deal with the inherent uncertainty associated with the model coefficients [18]. To build the problems, in practice, information about the variation interval of some of the parameters is required, which implies a simplification in comparison to other techniques, such as stochastic programming or fuzzy programming, which need the specification or the assumption of probabilistic and possibilistic distributions, respectively.

For interval MOLP problems, such as (2), it is not possible to obtain an optimal solution at which all the interval objective functions attain their individual optimum 
simultaneously, so we need to find a compromise solution. In multiobjective programming, these compromise solutions are the so-called efficient solutions; however, this type of solution cannot be defined for interval MOLP problems. Instead, definite efficiency and possible efficiency $[18,33-35]$ were considered as two natural extensions of the efficiency concept to interval MOLP problems (the formal definitions are hereafter). However, on the one hand, necessarily efficient solutions may not exist and, if they do exist, the computational burden required to find them is very high and increases with the number of interval coefficients on the objective function. On the other hand, there is usually an infinite number of possibly efficient solutions, which, in many cases, differ from one another marginally in the objective functions. Furthermore, it has been concluded that checking definite efficiency represents an NP-hard problem, even for the case of a single objective function $[18,36]$.

To alleviate these drawbacks, a methodological approach to generate possibly efficient solutions was proposed in [37]. Based on the use of an achievement scalarizing function [38], this approach combines the ideas of interval multiobjective programming suggested in [30] with a reference point-based approach [39]. This section of the paper represents a continuation of the work in [37]. In the following, we propose new singleobjective optimization problems to find solutions to interval MOLP problems. We establish an equivalence between the new proposal and the results of the previous work and propose three theorems with conditions to ensure the generation of possibly efficient solutions, and necessarily efficient solutions whenever they exist. The main advantage is that, by transforming the original model into a single objective problem, the computational effort required to obtain these types of solutions is greatly reduced.

Next, Section 3.1 describes the main background concepts used in interval multiobjective linear programming, and in Section 3.2, we present the new theoretical results.

\subsection{Concepts and Notation}

For an interval MOLP problem such as (2), each objective function does not attain a single value at every solution; instead, it can take values in a variation range for each solution; that is, for every $k=1, \ldots, p$, the values that the objective function $Z_{k}$ can take for each $\mathbf{x} \in X$ are within the following interval:

$$
Z_{k}(\mathbf{x}) \in\left[Z_{k}^{L}(\mathbf{x}), Z_{k}^{U}(\mathbf{x})\right], \text { where } Z_{k}^{L}(\mathbf{x})=\sum_{j}^{n} c_{k j}^{L} x_{j} \text { and } Z_{k}^{U}(\mathbf{x})=\sum_{j}^{n} c_{k j}^{U} x_{j} .
$$

In general, we can transform the interval MOLP problem given in (2) into a general MOLP problem by assuming that each of the coefficients in the objective functions takes a value within its corresponding interval; that is, if we consider a value $\bar{c}_{k j} \in\left[c_{k j}^{L}, c_{k j}^{U}\right]$ for every $k=1, \ldots, p$ and $j=1, \ldots, n$ in problem (2), the following MOLP problem would be obtained:

$$
\begin{array}{lll}
\operatorname{maximize} & \bar{Z}_{k}(\mathbf{x})=\sum_{j=1}^{n} \bar{c}_{k j} x_{j}, & k=1, \ldots, p, \\
\text { subject to } & \sum_{j=1}^{n} a_{i j} x_{j} \leq b_{i}, & i=1, \ldots, m, \\
& x_{j} \geq 0, & j=1, \ldots, n .
\end{array}
$$

As mentioned above, the concept of efficiency in multiobjective optimization [40] cannot be defined in a single manner in interval multiobjective programming. Instead, there are two types of efficient solutions: necessarily and possibly efficient solutions [18,33-35]. While the former are solutions that are efficient for at least one feasible combination of the objective function coefficients, the latter are solutions that are efficient for all the feasible combinations of the objective function coefficients [33].

To be more precise, it is worth noting that a solution $\mathbf{x}^{\prime} \in X$ is efficient for the MOLP problem (5) if and only if there is no other $\mathbf{x} \in X$ such that $\bar{Z}_{k}\left(\mathbf{x}^{\prime}\right) \leq \bar{Z}_{k}(\mathbf{x})$, for all $k=1, \ldots, p$, with at least one strict inequality. Then, for the interval MOLP problem (2), we say that $\mathbf{x}^{\prime} \in X$ is necessarily efficient if and only if it is efficient for the problem (5) for any 
$\bar{c}_{k j} \in\left[c_{k j}^{L}, c_{k j}^{U}\right]$, for all $k=1, \ldots, p$ and $j=1, \ldots, n$, while we consider that $\mathbf{x}^{\prime} \in X$ is possibly efficient if it is efficient for the problem (5) for at least one combination of $\bar{c}_{k j} \in\left[c_{k j}^{L}, c_{k j}^{U}\right]$, for $k=1, \ldots, p$ and $j=1, \ldots, n$. We refer to the sets of all necessarily and possibly efficient solutions as $N_{E}$ and $P_{E}$, respectively. Since a necessarily efficient solution is also a possibly efficient solution, we have $N_{E} \subset P_{E}$. In practice, a final solution to the problem (2) has to be selected among the solutions in $N_{E}$ or in $P_{E}$. Given that these sets are unknown beforehand, with no guarantees of having solutions in $N_{E}$ and with $P_{E}$ being a set that may have an infinite number of elements, a method to generate any of these types of solutions is usually required.

On the other hand, we can also extend the concept of an ideal objective vector in multiobjective optimization to the interval MOLP context [18]. For this purpose, for each objective function we need to calculate both its optimal value with the upper bounds of its coefficients and its optimal value with the lower bounds of its coefficients. Note that, if the objective is to be maximized (or minimized,respectively), the upper bounds (or lower bounds,respectively) of its coefficients represent the best possible scenario, while the lower bounds (or upper bounds, respectively) correspond to the worst possible scenario for this objective [41]. Therefore, to find the ideal objective values for the interval MOLP problem (2), we need to solve the following linear programming problems for each $k=1, \ldots, p$ :

$$
\begin{array}{lll}
\text { maximize } & Z_{k}^{U}(\mathbf{x})=\sum_{j=1}^{n} c_{k j}^{U} x_{j}, & \\
\text { subject to } & \sum_{j=1}^{n} a_{i j} x_{j} \leq b_{i}, & i=1, \ldots, m, \\
& x_{j} \geq 0, & j=1, \ldots, n . \\
\text { maximize } & Z_{k}^{L}(\mathbf{x})=\sum_{j=1}^{n} c_{k j}^{L} x_{j}, & \\
\text { subject to } & \sum_{j=1}^{n} a_{i j} x_{j} \leq b_{i}, & i=1, \ldots, m, \\
& x_{j} \geq 0, & j=1, \ldots, n .
\end{array}
$$

For every $k=1, \ldots, p, \mathbf{x}_{k}^{U}$ and $\mathbf{x}_{k}^{L}$ denote the optimal solutions to (6) and (7), respectively, and $Z_{k}^{U^{*}}=Z_{k}^{U}\left(x_{k}^{U}\right)$ and $Z_{k}^{L^{*}}=Z_{k}^{L}\left(x_{k}^{L}\right)$ denote their corresponding objective values. These objective values are the bounds of the interval ideal solution, which is defined by the intervals $\left[Z_{k}^{L^{*}}, Z_{k}^{U^{*}}\right]$ with $k=1, \ldots, p$.

\subsection{Solving Interval Molp Problems with a Scalarizing Approach}

As in [37], we assume that a decision maker, who is an expert in the problem domain, wants to minimize the distance of each objective function $Z_{k}$ to an interval target, denoted by $T_{k}=\left[t_{k}^{L}, t_{k}^{U}\right]$, representing a range of desirable values for $Z_{k}(k=1, \ldots, p)$. To achieve this, we can consider the deviations, by defect and by excess, of the values reached by each objective $Z_{k}$ to its interval target $T_{k}$ and minimize an aggregation of all the deviations. For each $T_{k}$, we refer to the deviations by defect as $e_{k}^{L}$ and $e_{k}^{U}$ and to the deviations by excess as $d_{k}^{L}$ and $d_{k}^{U}$ (with $e_{k}^{L}, e_{k}^{U}, d_{k}^{L}, d_{k}^{U} \geq 0$, for every $k=1, \ldots, p$ ).

Therefore, in order to find a feasible solution $\mathbf{x}=\left(x_{1}, \ldots, x_{n}\right)^{T}$ with the closest interval objective values (lying in $\left[Z_{k}^{L}(\mathbf{x}), Z_{k}^{U}(\mathbf{x})\right]$ for every $\left.k=1, \ldots, p\right)$ to the interval targets, we can solve the following scalarizing problem:

$$
\begin{array}{lll}
\text { minimize } & S\left(e_{1}^{L}, \ldots, e_{k}^{L}, e_{1}^{U}, \ldots, e_{k}^{U}, d_{1}^{L}, \ldots, d_{k}^{L}, d_{1}^{U}, \ldots, d_{k}^{U}\right) & \\
\text { subject to } & \sum_{j=1}^{n} c_{k j}^{L} x_{j}+e_{k}^{L}-d_{k}^{L}=t_{k}^{L}, & k=1, \ldots, p, \\
& \sum_{j=1}^{n} c_{k j}^{U} x_{j}+e_{k}^{U}-d_{k}^{U}=t_{k}^{U}, & k=1, \ldots, p, \\
& \sum_{j=1}^{n} a_{i j} x_{j} \leq b_{i}, & i=1, \ldots, m, \\
& x_{j} \geq 0, & j=1, \ldots, n,
\end{array}
$$

where $S\left(e_{1}^{L}, \ldots, e_{k}^{L}, e_{1}^{U}, \ldots, e_{k}^{U}, d_{1}^{L}, \ldots, d_{k}^{L}, d_{1}^{U}, \ldots, d_{k}^{U}\right)$ denotes an aggregation or scalarizing function of the deviations by defect and by excess to all the interval targets.

In particular, we can consider that the interval targets $T_{k}$ are defined by the bounds of the interval ideal solution, i.e., $T_{k}=\left[Z_{k}^{L *}, Z_{k}^{U *}\right]$ for every $k=1, \ldots, n$. In this case, the nec- 
essary deviations of the objective $Z_{k}$ to $T_{k}$ are defined by the interval $\left[e_{k}^{L}, e_{k}^{U}\right](k=1, \ldots, p)$ because we want to reach the interval ideal solution, which means that $d_{k}^{L}=d_{k}^{U}=0$ (since problem (2) is formulated in the maximization form). Additionally, the following scalarizing function can be used to aggregate these deviations:

$$
S\left(e_{1}^{L}, \ldots, e_{k}^{L}, e_{1}^{U}, \ldots, e_{k}^{U}\right)=\max _{k=1, \ldots, p}\left\{\mu_{k}^{L} e_{k}^{L}+\mu_{k}^{U} e_{k}^{U}\right\}
$$

where $\mu^{L}=\left(\mu_{1}^{L}, \ldots, \mu_{p}^{L}\right)^{T}$ and $\mu^{U}=\left(\mu_{1}^{U}, \ldots, \mu_{p}^{U}\right)^{T}$, with $\mu_{k}^{L}, \mu_{k}^{U}>0(k=1, \ldots, p)$, are vectors of weights denoting the importance assigned to achieve each of the deviations. Taking all of this into account, problem (8) would result in the following scalarizing problem:

$$
\begin{array}{lll}
\operatorname{minimize} & \max _{k=1, \ldots, p}\left\{\mu_{k}^{L} e_{k}^{L}+\mu_{k}^{U} e_{k}^{U}\right\} & \\
\text { subject to } & \sum_{j=1}^{n} c_{k j}^{L} x_{j}+e_{k}^{L}=Z_{k}^{L *}, & k=1, \ldots, p, \\
& \sum_{j=1}^{n} c_{k j}^{U} x_{j}+e_{k}^{U}=Z_{k}^{U *}, & k=1, \ldots, p, \\
& \sum_{j=1}^{n} a_{i j} x_{j} \leq b_{i}, & i=1, \ldots, m, \\
& x_{j} \geq 0, & j=1, \ldots, n .
\end{array}
$$

As can be noted, this problem is based on a minimax approach formulated using an additive term with the necessary deviations to each interval of the ideal solution. Thus, by solving this problem, we can find a feasible solution to problem (2) whose interval objective values are as close as possible to the bounds of the interval ideal solution.

In [37], it was stated that, if the optimal solution to the following problem is unique, then it is a possibly efficient solution to the original interval MOLP problem (2):

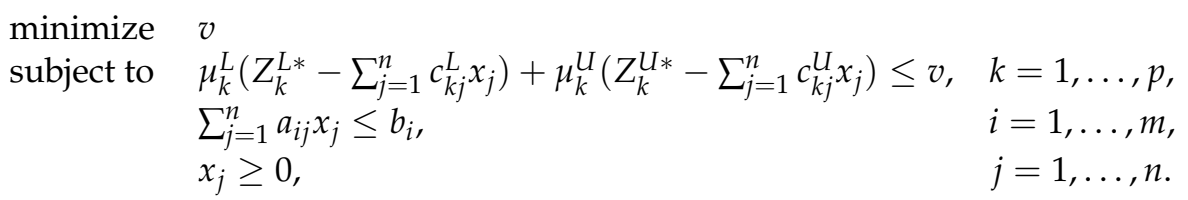

With the following result, we demonstrate that, if the optimal solution to problem (10) is unique, then it is also a possibly efficient solution to (2). This theorem is supported by the fact that any optimal solution to (10) is also optimal to problem (11) (which is demonstrated in the proof of this theorem):

Theorem 1. Let $\mathbf{x}^{*}=\left(x_{1}^{*}, \ldots, x_{n}^{*}\right)^{T}$ and $e_{k}^{* L}, e_{k}^{* U}$, for $k=1, \ldots, p$, be an optimal solution to problem (10), where $\mu_{k}^{L}, \mu_{k}^{U}>0$ and $\mu_{k}^{L}+\mu_{k}^{U}=1$ for all $k=1, \ldots, p$. If $\mathbf{x}^{*}$ is unique, then it is a possibly efficient solution to problem (2).

Proof. See Appendix A.

The requirement of uniqueness of the solution can be suppressed if we add an augmentation term to the scalarizing function used in problem (10); that is, we can consider the following scalarizing function instead of (9):

$$
S\left(e_{1}^{L}, \ldots, e_{k}^{L}, e_{1}^{U}, \ldots, e_{k}^{U}\right)=\max _{k=1, \ldots, p}\left\{\mu_{k}^{L} e_{k}^{L}+\mu_{k}^{U} e_{k}^{U}\right\}+\rho \sum_{k=1}^{p}\left(\mu_{k}^{L} e_{k}^{L}+\mu_{k}^{U} e_{k}^{U}\right),
$$


where $\rho>0$ is a so-called augmentation coefficient. Thus, problem (8) would be formulated as:

$$
\begin{array}{llr}
\operatorname{minimize} & \max _{k=1, \ldots, p}\left\{\mu_{k}^{L} e_{k}^{L}+\mu_{k}^{U} e_{k}^{U}\right\}+\rho \sum_{k=1}^{p}\left(\mu_{k}^{L} e_{k}^{L}+\mu_{k}^{U} e_{k}^{U}\right) & \\
\text { subject to } & \sum_{j=1}^{n} c_{k j}^{L} x_{j}+e_{k}^{L}=Z_{k}^{L *}, & k=1, \ldots, p, \\
& \sum_{j=1}^{n} c_{k j}^{U} x_{j}+e_{k}^{U}=Z_{k}^{U *}, & k=1, \ldots, p, \\
& \sum_{j=1}^{n} a_{i j} x_{j} \leq b_{i}, & i=1, \ldots, m, \\
& x_{j}, e_{k}^{L}, e_{k}^{U} \geq 0, & j=1, \ldots, n, k=1, \ldots, p .
\end{array}
$$

In [37], the optimal solution to the following problem was also shown to be a possibly efficient solution to problem (2):

$$
\begin{array}{cll}
\text { minimize } & v+\rho \sum_{k=1}^{p}\left(\mu_{k}^{L}\left(Z_{k}^{L *}-\sum_{j=1}^{n} c_{k j}^{L} x_{j}\right)+\mu_{k}^{U}\left(Z_{k}^{U *}-\sum_{j=1}^{n} c_{k j}^{U} x_{j}\right)\right) & \\
\text { subject to } & \mu_{k}^{L}\left(Z_{k}^{L *}-\sum_{j=1}^{n} c_{k j}^{L} x_{j}\right)+\mu_{k}^{U}\left(Z_{k}^{U *}-\sum_{j=1}^{n} c_{k j}^{U} x_{j}\right) \leq v, & k=1, \ldots, p, \\
& \sum_{j=1}^{n} a_{i j} x_{j} \leq b_{i}, & i=1, \ldots, m, \\
& x_{j} \geq 0, & j=1, \ldots, n .
\end{array}
$$

By demonstrating that an optimal solution to problem (13) is also an optimal solution to (14), we can formulate the following theorem to guarantee that the optimal solution to (13) is a possibly efficient solution to the original problem (2).

Theorem 2. Let $\mathbf{x}^{*}=\left(x_{1}^{*}, \ldots, x_{n}^{*}\right)^{T}$ and $e_{k}^{* L}, e_{k}^{* U}$, for $k=1, \ldots, p$, be an optimal solution to problem (13), where $\mu_{k}^{L}, \mu_{k}^{U}>0$ and $\mu_{k}^{L}+\mu_{k}^{U}=1$ for all $k=1, \ldots, p$. Then, $\mathbf{x}^{*}$ is a possibly efficient solution to problem (2).

Proof. See Appendix A.

Finally, with the next theorem, we prove that if the objective value at an optimal solution to problem (10) is zero, then this solution is also a necessarily efficient solution to the original problem (2).

Theorem 3. Let $\mathbf{x}^{*}=\left(x_{1}^{*}, \ldots, x_{n}^{*}\right)^{T}$ and $e_{k}^{* L}, e_{k}^{* U}$, for $k=1, \ldots, p$, be an optimal solution to problem (10), where $\mu_{k}^{L}, \mu_{k}^{U}>0$ and $\mu_{k}^{L}+\mu_{k}^{U}=1$ for all $k=1, \ldots, p$. If the optimal objective value at $\mathbf{x}^{*}$ is 0 , then $\mathbf{x}^{*}$ is a necessarily efficient solution to problem (2).

Proof. See Appendix A.

To summarize, the new scalarizing approaches (10) and (13) proposed allow us to generate possibly efficient solutions to interval MOLP problems, by minimizing the maximum of the weighted distances to the lower and upper ideal values. Furthermore, necessarily efficient solutions can also be obtained with problem (10) if the minimum value is 0 .

As shown in the next section, the new formulations were used in practice to generate solutions to the interval MOLP problems (3) and (4) built to study the improvement of students' well-being in Spain and Finland. In particular, problems (6) and (7) were used to calculate the interval ideal values of these two models, and problem (13) was applied to find possibly efficient solutions to both the Spanish and the Finnish cases.

\section{Results}

To investigate how to improve the four well-being indexes in Spain and Finland, first, we calculated the interval ideal values of the four objective functions in the interval MOLP models (3) and (4). This enabled us to have an initial idea of their best possible individual values under the worst and the best possible scenarios, respectively. For this purpose, we 
obtained the individual optimum of each objective function using the lower and upper bounds of its interval coefficients, i.e., we formulated and solved the problems given in (6) and (7) for each objective in models (3) and (4), respectively.

The lower and upper optimal values of the four indicators are shown in Table 7. It is worth noting that the first three objective functions (positive feelings, motivation and sense of belonging indexes) must be maximized, while the last one (bullying index) must be minimized. We can observe that the interval ideal values for Finland are better than those for Spain, which is in line with the conclusions in the PISA 2018 report [6].

Table 7. Interval ideal values of each objective function in models (3) and (4).

\begin{tabular}{clccc}
\hline & Well-Being Indexes & & Lower Ideal Value $\left(Z_{k}^{L *}\right)$ & Upper Ideal Value $\left(Z_{k}^{U *}\right)$ \\
\hline \multirow{4}{*}{ Spain } & Positive feelings & $Z_{1}$ & 0.0717 & 0.6020 \\
& Motivation & $Z_{2}$ & 0.1184 & 0.9872 \\
& Sense of belonging & $Z_{3}$ & 0.0292 & 0.6637 \\
& Bullying & $Z_{4}$ & -0.7406 & -0.0838 \\
\hline \multirow{5}{*}{ Finland } & Positive feelings & $Z_{1}$ & 0.5184 & 1.0513 \\
& Motivation & $Z_{2}$ & 0.4861 & 1.3795 \\
& Sense of belonging & $Z_{3}$ & 0.2496 & 0.8388 \\
& Bullying & $Z_{4}$ & -0.8693 & -0.3924 \\
\hline
\end{tabular}

To generate solutions to these problems, we gave the same level of concentration to the achievement of the optimistic and the pessimistic scenarios (i.e., the best and the worst possible scenarios) defined by the interval ideal values shown in Table 7. Note that, in our study, the optimistic scenario is defined by the upper ideal values for positive feelings, motivation and sense of belonging, and the lower ideal value for bullying, while the pessimistic scenario corresponds to the lower ideal values for positive feelings, motivation and sense of belonging, and the upper ideal value for bullying. To find balanced optimal solutions between both scenarios, we formulated and solved the scalarizing problem (13) for problems (3) and (4), using the same weights for all objectives in both scenarios (i.e., $\mu_{k}^{L}=\mu_{k}^{U}=1$ for every $\left.k=1, \ldots, p\right)$.

The solutions obtained for Spain and Finland, denoted by $\overline{\mathbf{x}}^{S}$ and $\overline{\mathbf{x}}^{F}$, respectively, can be seen in Table 8 (decision variable values) and in Table 9 (interval objective function values). These solutions are guaranteed to be possibly efficient according to the theoretical results provided in Section 3.2. In order to measure how close solutions $\overline{\mathbf{x}}^{S}$ and $\overline{\mathbf{x}}^{F}$ are to their interval ideal solutions (shown in Table 7), we also computed the following distances:

$$
\begin{array}{ll}
d_{k}\left(\overline{\mathbf{x}}^{S}\right)=\max \left(\left|Z_{k}^{L^{*}}-Z_{k}^{L}\left(\overline{\mathbf{x}}^{S}\right)\right|,\left|Z_{k}^{U^{*}}-Z_{k}^{U}\left(\overline{\mathbf{x}}^{S}\right)\right|\right. & \text { for } k=1,2,3,4, \\
d_{k}\left(\overline{\mathbf{x}}^{F}\right)=\max \left(\left|Z_{k}^{L^{*}}-Z_{k}^{L}\left(\overline{\mathbf{x}}^{F}\right)\right|,\left|Z_{k}^{U^{*}}-Z_{k}^{U}\left(\overline{\mathbf{x}}^{F}\right)\right|\right. & \text { for } k=1,2,3,4 .
\end{array}
$$

The results obtained are reported in Table 10 . Note that for any $k=1,2,3,4$, having a distance $d_{k}$ near zero means that the interval values for the objective $Z_{k}$ at this solution are close to its ideal interval values $\left[Z_{k}^{L^{*}}, Z_{k}^{U^{*}}\right]$.

Table 8. Possibly efficient solutions obtained to problems (3) and (4).

\begin{tabular}{lccc}
\hline \multicolumn{1}{c}{ Decision Variables } & & Spain $\left(\overline{\mathbf{x}}^{S}\right)$ & Finland $\left(\overline{\mathbf{x}}^{F}\right)$ \\
\hline Socioeconomic index & $x_{1}$ & 3.7171 & 2.3691 \\
School type & $x_{2}$ & 1.0000 & 0.0000 \\
Gender & $x_{3}$ & 1.0000 & 0.0000 \\
Internet outside school & $x_{4}$ & 2.4616 & 0.0000 \\
Starting age for using digital devices & $x_{5}$ & 7.0996 & 5.0855 \\
Teacher support & $x_{6}$ & -0.9723 & -0.9294 \\
Disciplinary climate & $x_{7}$ & 1.4652 & -2.4839 \\
Foreign language & $x_{8}$ & 5.0855 & 4.6389 \\
\hline
\end{tabular}


Table 9. Optimal interval objective values at the solutions to problems (3) and (4).

\begin{tabular}{clcccc}
\hline & Well-Being Indexes & & $\begin{array}{c}\text { Lower Objective } \\
\text { Values }\left(Z_{k}^{L}\right)\end{array}$ & $\begin{array}{c}\text { Upper Objective } \\
\text { Values }\left(Z_{k}^{U}\right)\end{array}$ & $\begin{array}{c}\text { Mean Objective } \\
\text { Values }\end{array}$ \\
\hline \multirow{5}{*}{ Spain $\left(\overline{\mathbf{x}}^{S}\right)$} & Positive feelings & $Z_{1}$ & -0.0256 & 0.5987 & 0.2866 \\
& Motivation & $Z_{2}$ & 0.1016 & 0.9050 & 0.5033 \\
& Sense of belonging & $Z_{3}$ & -0.0769 & 0.6275 & 0.2753 \\
& Bullying & $Z_{4}$ & -0.6737 & -0.0829 & -0.3783 \\
\hline \multirow{5}{*}{ Finland $\left(\overline{\mathbf{x}}^{F}\right)$} & Mositive feelings & $Z_{1}$ & 0.5173 & 0.8035 & 0.6604 \\
& Setivation & $Z_{2}$ & 0.4273 & 0.9159 & 0.6716 \\
& Bullying & $Z_{3}$ & 0.1243 & 0.4453 & 0.2848 \\
& $Z_{4}$ & -0.0970 & 0.0057 & -0.0457 \\
\hline
\end{tabular}

Table 10. Distances of the interval objective values of the solutions $\overline{\mathbf{x}}^{S}$ and $\overline{\mathbf{x}}^{F}$ to their interval ideal solution.

\begin{tabular}{lccc}
\hline Well-Being Indexes & & Spain $\left(\boldsymbol{d}_{\boldsymbol{k}}\left(\overline{\mathbf{x}}^{S}\right)\right)$ & Finland $\left(\boldsymbol{d}_{\boldsymbol{k}}\left(\overline{\mathbf{x}}^{F}\right)\right)$ \\
\hline Positive feelings & $Z_{1}$ & 0.0973 & 0.2478 \\
Motivation & $Z_{2}$ & 0.1082 & 0.4636 \\
Sense of belonging & $Z_{3}$ & 0.1061 & 0.3935 \\
Bullying & $Z_{4}$ & 0.0669 & 0.8750 \\
\hline
\end{tabular}

In practice, the solutions $\overline{\mathbf{x}}^{S}$ and $\overline{\mathbf{x}}^{F}$ depict the profiles of the Spanish and Finnish students, respectively, who attained an optimum balance among the four well-being indexes, as well as compromise values for both the optimistic and the pessimistic scenarios, in each country. The main findings can be summarized as follows. The socioeconomic index variable in both solutions reached the maximum sample value for each country. In Spain, the student with the optimal balance is enrolled in a semi-private school, while in Finland, (s)he should ideally study in a public school (which is not surprising given that most Finnish schools are public). Additionally, the profile of the Spanish student is associated with girls, while in Finland, the optimal profile is identified with boys. It is interesting to note that, in Spain, this student should ideally spend $2.46 \mathrm{~h}$ surfing the web outside school and should have ideally had their first contact with digital devices at the age of 7, while the Finnish one should not use the Internet and should have started using digital devices at 5 years old.

The teacher support variable reached very similar levels in both solutions, with levels very close to their corresponding minimum sample values. Since this variable is of the "less is better" type, this reveals the importance of the support received from teachers to have an optimal well-being level among adolescents (in terms of the indexes considered here). Nevertheless, the value of the disciplinary climate variable is near to the maximum sample value in the Spanish solution, but it obtained a value very close to the minimum of the sample in the Finnish solution. This indicates that, in Spain, stricter discipline at school is beneficial for the well-being of students, while having a less strict climate is more positive in Finland for achieving well-being. Additionally, the ideal number of class periods to be taught in a foreign language should be around five in Spain, and between 4 and 5 in Finland.

Regarding the objective function values at $\overline{\mathbf{x}}^{S}$ and $\overline{\mathbf{x}}^{F}$, the Spanish student seems to have reached an optimal balance among the four well-being indexes that, overall, is closer to the ideal situation than that attained by the Finnish student, because the distances shown in Table 10 for $\overline{\mathbf{x}}^{S}$ are closer to zero than those for $\overline{\mathbf{x}}^{F}$. In fact, we can see in Table 9 that the optimal Spanish student achieved objective functions that are very close to their ideal levels for the four well-being indexes, both in the pessimistic scenario (i.e., lower values for the first three objectives and upper value for the last objective) and the optimistic scenario (i.e., upper values for the first three objectives and lower value for the last objective). 
Concerning the optimal student in Finland, only positive feelings and motivation obtained optimal values that are very close to their ideals in the pessimistic scenario, while the optimistic scenario is more difficult to reach for the four indexes. Note that achieving these levels for positive feelings and motivation in Finland's pessimistic scenario is directly related to the fact that, ideally, the optimal Finnish student should not be connected to the Internet outside school (see Table 8). In fact, this is supported by the initial findings observed in the econometric analysis described in Section 2.2, where we concluded that Finnish students spending less time on the Internet showed better levels of positive feelings and were more motivated. On the other hand, in Finland, the bullying index is the objective that attained the objective values furthest from the ideal optimistic and pessimistic values. This fact reveals that bullying is the most sacrificed aspect when compromise optimal levels for the four well-being indexes compete to be reached at the same time. In practice, this means that it is very difficult to improve the situation of the bullied students in Finland so as to find a balanced improvement of the four indicators.

Additionally, we can analyze the scope for improvement in each country, taking into account students' current situations. For this purpose, we compared the means of the optimal interval objective values in the solutions found (shown in the last column of Table 9) with the sample mean values of the well-being indicators (given in Table 2). In the case of Spain, on average, the highest improvement that can be achieved is associated with students' motivation, with the other indexes enhancing their current mean values but to a lower extent. In Finland, both positive feelings and motivation are the most enhanced, with a very similar amount of improvement. Note that the comparison of the mean sample value and the mean optimal value for bullying in this country corroborates our previous conclusions and indicates that the situation of bullying of Finnish students can be improved at a very low rate.

\section{Comparative Study of the Proposed Methodology}

In this section, we show the benefits of the methodology proposed for interval multiobjective linear programming in comparison to a classical deterministic multiobjective optimization technique. For this purpose, we obtained a deterministic model using the data of each country, in which the objective functions representing the well-being indexes are formulated using fixed values (instead of intervals) to define their coefficients. As a result, MOLP problems such as that given in (5) were obtained for Spain and Finland. Specifically, we set the objective functions' coefficients as the regression coefficients of model (1), which are the mean values of the confidence intervals given in Tables 3 and 4 . The deterministic formulations for the objective functions are provided in Table 11. The sets of constraints defining the feasible solutions for Spain and Finland are the same as in models (3) and (4).

To obtain solutions to the resulting MOLP models following a similar methodology to the one proposed in Section 3.2, we used a deterministic approach based on a scalarizing function. In this approach, the achievement scalarizing function proposed in [38] was minimized over the feasible set of solutions, in order to find the Pareto optimal solution, which is the one closest to a reference point composed of desirable reference values for the objective functions. We considered the ideal objective function values as desirable reference levels for the well-being indexes. For Spain and Finland, these ideal values were calculated by individually optimizing each deterministic objective function over the corresponding feasible set of solutions. Table 12 contains the ideal objective vectors obtained in this way. The solutions obtained by means of this deterministic approach for the Spanish and Finnish models are shown in Table 13 (decision variable values) and Table 14 (objective function values). As can be seen, the solutions obtained for Spain and Finland only provide us with information about one optimal value for each well-being index, while the solutions generated by the proposed interval multiobjective optimization approach allow us to gain further insights into the range of possible optimal values that each indicator can reach (see Table 9). 
Table 11. Deterministic formulations of the objective functions for Spain and Finland.

\begin{tabular}{lll}
\hline Well-Being Indexes & Max/ Min & Formulation \\
\hline Spain & & \\
\hline Positive feelings & Max & $\hat{Z}_{1}=0.0280 \cdot x_{1}-0.0559 \cdot x_{3}+0.0087 \cdot x_{5}-0.0873 \cdot x_{6}+0.0560 \cdot x_{7}+0.0101$ \\
Motivation & Max & $\hat{Z}_{2}=0.0345 \cdot x_{1}+0.1719 \cdot x_{3}-0.0311 \cdot x_{4}+0.0151 \cdot x_{5}-0.1367 \cdot x_{6}+0.0292 \cdot x_{7}+0.0258 \cdot x_{8}-0.1341$ \\
Sense of belonging & Max & $\hat{Z}_{3}=0.0410 \cdot x_{1}+0.0952 \cdot x_{2}-0.0604 \cdot x_{3}+0.0229 \cdot x_{4}-0.1106 \cdot x_{6}+0.0622 \cdot x_{7}-0.1668$ \\
Bullying & Min & $\hat{Z}_{4}=-0.1244 \cdot x_{3}+0.0121 \cdot x_{4}+0.0607 \cdot x_{6}-0.1023 \cdot x_{7}-0.0167 \cdot x_{8}+0.0104$ \\
\hline Finland & & \\
\hline Positive feelings & Max & $\hat{Z}_{1}=0.1154 \cdot x_{1}+-0.0727 \cdot x_{4}-0.1270 \cdot x_{6}+0.0316 \cdot x_{7}+0.3473$ \\
Motivation & Max & $\hat{Z}_{2}=0.1720 \cdot x_{1}+0.1145 \cdot x_{3}-0.0875 \cdot x_{4}-0.1154 \cdot x_{6}+0.0329 \cdot x_{7}+0.0258 \cdot x_{8}+0.1190$ \\
Sense of belonging & Max & $\hat{Z}_{3}=0.0713 \cdot x_{1}+-0.2000 \cdot x_{2}+-0.2312 \cdot x_{3}-0.0325 \cdot x_{4}-0.0960 \cdot x_{6}+0.0658 \cdot x_{7}+0.1900$ \\
Bullying & Min & $\hat{Z}_{4}=-0.1275+\cdot x_{3}+0.0417 \cdot x_{4} \cdots+0.1169 \cdot x_{6}-0.1160 \cdot x_{7}-0.2252$ \\
\hline
\end{tabular}

Table 12. Ideal objective values of the deterministic problems for Spain and Finland.

\begin{tabular}{|c|c|c|c|}
\hline & Well-Being Indexes & & Ideal Objective Values $\left(\hat{Z}_{k}^{*}\right)$ \\
\hline \multirow{4}{*}{ Spain } & Positive feelings & $\hat{Z}_{1}$ & 0.3368 \\
\hline & Motivation & $\hat{Z}_{2}$ & 0.5033 \\
\hline & Sense of belonging & $\hat{Z}_{3}$ & 0.3465 \\
\hline & Bullying & $\hat{Z}_{4}$ & -0.3783 \\
\hline \multirow{4}{*}{ Finland } & Positive feelings & $\hat{Z}_{1}$ & 0.5863 \\
\hline & Motivation & $\hat{Z}_{2}$ & 0.5033 \\
\hline & Sense of belonging & $\hat{Z}_{3}$ & 0.3465 \\
\hline & Bullying & $\hat{\mathrm{Z}}_{4}$ & -0.3783 \\
\hline
\end{tabular}

Table 13. Pareto optimal solutions obtained to the deterministic problems for Spain and Finland.

\begin{tabular}{lccc}
\hline \multicolumn{1}{c}{ Decision Variables } & & Spain & Finland \\
\hline Socioeconomic index & $x_{1}$ & 3.7171 & 2.3691 \\
School type & $x_{2}$ & 1.0000 & 0.0000 \\
Gender & $x_{3}$ & 1.0000 & 0.0000 \\
Internet outside school & $x_{4}$ & 2.4616 & 2.7310 \\
Starting age for using digital devices & $x_{5}$ & 7.0996 & 6.2587 \\
Teacher support & $x_{6}$ & -0.9723 & -0.9294 \\
Disciplinary climate & $x_{7}$ & 1.4652 & 1.4607 \\
Foreign language & $x_{8}$ & 5.0855 & 7.0000 \\
\hline
\end{tabular}

Table 14. Objective values at the Pareto optimal solutions obtained for the deterministic problems for Spain and Finland.

\begin{tabular}{clcc}
\hline & Well-Being Indexes & & Objective Values \\
\hline \multirow{4}{*}{ Spain } & Positive feelings & $\hat{Z}_{1}$ & 0.2866 \\
& Motivation & $\hat{Z}_{2}$ & 0.4795 \\
& Sense of belonging & $\hat{Z}_{3}$ & 0.2928 \\
& Bullying & $\hat{Z}_{4}$ & -0.3691 \\
\hline \multirow{4}{*}{ Finland } & Positive feelings & $\hat{Z}_{1}$ & $0, .5849$ \\
& Motivation & $\hat{Z}_{2}$ & 0.6232 \\
& Sense of belonging & $\hat{Z}_{3}$ & 0.4564 \\
& Bullying & $\hat{Z}_{4}$ & -0.3885 \\
\hline
\end{tabular}


As described above, when solving the problem by means of a deterministic approach, we formulated the models with the mean values of the regression coefficients, instead of considering the data information contained in their confidence intervals, which are more representative of the situation under scrutiny. The proposed approach of interval multiobjective optimization programming is able to better reflect the richness of the observational data and allows us to obtain solutions that are better suited to the reality under consideration. Furthermore, the results obtained with our methodology provide compromise solutions which are efficient under different scenarios of the well-being indexes (represented in the model thanks to the intervals used to define the coefficients of the objective functions). This type of information is not given by the deterministic approach we used, which is only able to generate a solution that is Pareto optimal for one of the possible situations defining the indexes considered.

On the other hand, solving interval mutiobjective optimization problems is an NP-hard problem, as indicated in Section 3, which means that the computational effort required to solve these models increases exponentially. This is a disadvantage of the proposed methodology in comparison to, e.g., the deterministic approach used.

\section{Discussion and Conclusions}

This paper analyzes the trade-offs existing between four indexes that measure different aspects of students' well-being, by means of econometric techniques and interval multiobjective programming approaches. Specifically, we studied how the well-being of students could be enhanced in Spain and Finland, as a way to promote their academic achievement. For each country, we defined an interval multiobjective linear programming problem, in which the objective functions were formulated using the confident intervals of the coefficients regressing the well-being indexes as functions of a set of explanatory variables. The resulting models were solved using desirable preferences (given as pessimistic and optimistic scenarios for each of the indexes), in order to investigate the profile of each country's student with the best (optimal) level of well-being; that is, the student who achieves, at the same time, optimal compromise values for the four indicators considered.

The main benefit of the methodological approach applied, combining econometric and interval multiobjective programming techniques, is that it allows the level to which students' well-being can be promoted under several scenarios to be determined, shedding light on the sacrifices needed in some of the indexes to reach certain improvements in others. This kind of information, rarely obtained by econometric models alone, can help educational authorities in defining measures to improve the well-being of adolescents and to foresee the future impacts of the policies contemplated. In addition, from a theoretical point of view, we also proposed a scalarizing approach for interval multiobjective linear programming that simplifies the generation of solutions to these types of models. Three theorems provide conditions to assure the generation of possibly and necessarily efficient solutions for interval MOLP problems.

Overall, our findings suggest several differences between the students attaining optimum well-being in Spain and Finland. In Spain, the student with compromise values among the four indicators corresponds to a girl enrolled in a semi-private school. This suggests that educational authorities should make greater efforts to enhance the well-being of students at public schools. In Finland, the optimal student is a boy studying in a public school. This fact may be linked to the under-representation of private schools in Finland.

Another difference relates to the time spent using the Internet outside school: ideally, in Spain, the optimal student should be connected to the Internet for about two hours and a half, while in Finland no time should be spent on the web outside school. Additionally, it was detected that the optimal Spanish student should have started using digital devices two years later than the Finnish one. This sheds some light on the impact of the use of ICT on students' well-being, with different implications in each country. The results for Spain are in line with studies such as [42], in which authors emphasized that the use of the Internet by adolescents, especially those with additional support needs, allows them to 
engage in activities which support the development of identity, competence and a sense of connectedness and belonging to a social network, which is essential to reach good levels of well-being. Furthermore, the Internet and ICT can be very helpful for students who usually have less opportunities to build social networks offline (such as those with an autistic spectrum disorder) to do so. Nevertheless, at the same time, a responsible use of the Internet and ICT should be promoted among young people when improving their well-being, in order to avoid negative risks associated with using them in excess, such as Internet addiction and school disconnectedness [43].

Particularly interesting is the fact that to reach optimal well-being, discipline in Spain should be stricter, while the Finnish student should ideally study in a more relaxed climate, less strict than the current one. The definition of the disciplinary climate variable used in our study is connected with the so-called positive discipline, which applies positive and supportive teacher-student relations to guide and discipline students. In the literature, several authors have also stated that a positive discipline facilitates students' well-being and effective teaching [44-46]. As mentioned in [44], the key of positive discipline is not reaching a short-term effect by punishing or restricting students, but using positive strategies to guide them to develop good behaviour and achieve self-discipline in the long term. Therefore, positive discipline strategies mainly involve skills and manners through which positive emotions and thinking are promoted in students to encourage learning, as well as methods for improving students' mental health and preventing behavioral problems. Our findings indicate that educational policies should be developed to increase these types of positive discipline activities in school classes.

On the other hand, the support that students receive from teachers should be promoted in both countries, since both optimal solutions attain better teacher support values than their sample mean levels. This reveals the key role of teacher support for increasing students' well-being in both countries, in line with the findings provided in [46]. Hence, this situation deserves special attention from educational authorities when designing policies to enhance students' lives and, therefore, their academic achievements. In this regard, in [47], it was also concluded that adolescents' perception of teacher support accounted for their well-being, and it was stated that "students perceive teachers to be supportive primarily when they attempt to connect with students on an emotional level, use diverse and best-practice teaching strategies, acknowledge and boost students' academic success, demonstrate fairness during interactions with students, and foster a classroom environment in which questions are encouraged". Therefore, these types of attitudes and methods must be promoted among teachers to positively affect their students' well-being.

Regarding the improvement of well-being that could be attained in the future, it seems that the students' situation in Spain could be enhanced further than in Finland. Indeed, it is more feasible to reach the ideal situation in Spain than in Finland. Overall, the motivation index is the aspect that could reach the highest improvement in both countries. Thus, special attention should be given to the development of measures to motivate students, such as implementing protocols to engage students in an autonomous way and encouraging them to participate in their own learning.

Moreover, it is difficult to minimize the current levels of bullying in Finland. In fact, this indicator has shown the lowest improvement rate, on average. This indicates that authorities should re-consider current anti-bullying programs and develop new educational policies to avoid bullying behaviors and reduce the current figures. For example, the KiVa Anti-Bullying Program [48] implemented in Finland has obtained very positive results with actions to support bullied students and activities to increase empathy towards them. However, the current analysis suggests that greater efforts should be made to avoid this phenomenon.

In future research work, we would like to develop a web application for schools to detect students with bad levels of well-being based on the indexes studied in this paper, especially to identify students suffering bullying due to the negative impact of this aspect on their lives. With the help of educational decision makers, this web application could 
be used to design policies to avoid undesired scenarios, taking into account the specific characteristics of each center, and giving different priorities to the enhancement of each well-being index according to students' needs.

Author Contributions: Conceptualization, S.G.-G., A.B.R. and M.L.; methodology, S.G.-G. and M.L.; software, S.G.-G. and M.L.; validation, A.B.R.; formal analysis, S.G.-G. and M.L.; investigation, S.G.-G. and M.L.; resources, S.G.-G.; data curation, S.G.-G.; writing_-original draft preparation, M.L. and S.G.-G.; writing-review and editing, A.B.R.; visualization, S.G.-G. and A.B.R.; supervision, A.B.R. and M.L.; project administration, M.L.; funding acquisition, M.L. and A.B.R. All authors contributed equally to this work. All authors have read and agreed to the published version of the manuscript.

Funding: This research was funded by the Spanish Ministry of Economy and Competitiveness (grant number ECO2017-88883-R), by the Andalusian Regional Ministry of Economy, Knowledge, Business and University (PAI group SEJ-532 and grant number UMA18-FEDERJA-024) and by the University of Málaga (grant number B1-2020_18). Sandra González-Gallardo is recipient of a technical research contract within "Sistema Nacional de Garanta Juvenil y del Programa Operativo de Empleo Juvenil 2014-2020-Fondos FEDER".

Institutional Review Board Statement: Not applicable.

Informed Consent Statement: Not applicable.

Data Availability Statement: Publicly available datasets were analyzed in this study (2018). These data can be found here: https: / / www.oecd.org/pisa/pisa-2018-results-in-focus.pdf (accessed on 20 June 2021).

Conflicts of Interest: The authors declare no conflict of interest.

\section{Appendix A}

Theorem A1. Let $\mathbf{x}^{*}=\left(x_{1}^{*}, \ldots, x_{n}^{*}\right)^{T}$ and $e_{k}^{* L}, e_{k}^{* U}$, for $k=1, \ldots, p$, be an optimal solution to problem (10), where $\mu_{k}^{L}, \mu_{k}^{U}>0$ and $\mu_{k}^{L}+\mu_{k}^{U}=1$ for all $k=1, \ldots, p$. If $\mathbf{x}^{*}$ is unique, then it is a possibly efficient solution to problem (2).

Proof. It is apparent that any optimal solution to problem (10) is also an optimal solution to problem (11). If we consider:

$$
v^{*}=\max _{k=1, \ldots, p}\left\{\mu_{k}^{L} e_{k}^{* L}+\mu_{k}^{U} e_{k}^{* U}\right\},
$$

we demonstrate that $\mathbf{x}^{*}$ and $v^{*}$ are also optimal to problem (11) by reductio ad absurdum. Therefore, we assume that this solution is not efficient to (11), and $\overline{\mathbf{x}}=\left(\bar{x}_{1}, \ldots, \bar{x}_{n}\right)^{T}$ and $\bar{v}$ denote an optimal solution to (11). Obviously, this means that $\bar{v}<v^{*}$.

According to the constraints of problem (11), we have the following:

$$
\bar{v}=\max _{k=1, \ldots, p}\left\{\mu_{k}^{L}\left(Z_{k}^{L *}-\sum_{j=1}^{n} c_{k j}^{L} \bar{x}_{j}\right)+\mu_{k}^{U}\left(Z_{k}^{U *}-\sum_{j=1}^{n} c_{k j}^{U} \bar{x}_{j}\right)\right\} .
$$

If we consider $\bar{e}_{k}^{L}$ and $\bar{e}_{k}^{U}$ defined as follows:

$$
\begin{array}{ll}
\bar{e}_{k}^{L}=Z_{k}^{L *}-\sum_{j=1}^{n} c_{k j}^{L} \bar{x}_{j,} & k=1, \ldots, p, \\
\bar{e}_{k}^{U}=Z_{k}^{U *}-\sum_{j=1}^{n} c_{k j}^{U} \bar{x}_{j}, & k=1, \ldots, p,
\end{array}
$$

we can say that:

$$
\bar{v}=\max _{k=1, \ldots, p}\left\{\mu_{k}^{L} \bar{e}_{k}^{L}+\mu_{k}^{U} \bar{e}_{k}^{U}\right\} .
$$

Therefore, considering the definition of $v^{*}$ and that $\bar{v}<v^{*}$, it holds that:

$$
\max _{k=1, \ldots, p}\left\{\mu_{k}^{L} \bar{e}_{k}^{L}+\mu_{k}^{U} \bar{e}_{k}^{U}\right\}<\max _{k=1, \ldots, p}\left\{\mu_{k}^{L} e_{k}^{*}+\mu_{k}^{U} e_{k}^{*}\right\} .
$$


This contradicts the fact that $\mathbf{x}^{*}, e_{k}^{* U}, e_{k}^{* L}$, for $k=1, \ldots, p$, is an optimal solution to problem (10), given that $\overline{\mathbf{x}}, \bar{e}_{k}^{L}, \bar{e}_{k}^{U}$, for $k=1, \ldots, p$, would be a feasible solution to this problem with an objective value lower than its optimal objective value.

In this regard, the theorem is proven, since we know that every optimal solution to problem (10) is also an optimal solution to (11). Note that, if this optimal solution is unique to problem (10), then it is also the unique optimal solution to problem (11) (by reductio ad absurdum, if an optimal solution is unique for (10) and we suppose that it is not unique for (11), similarly, we would find an optimal solution to problem (10) different to the initial one, and this would contradict the uniqueness condition). According to [37] (Theorem 1), all of this implies that $\mathbf{x}^{*}$ is a possibly efficient solution to the interval MOLP problem (2).

Theorem A2. Let $\mathbf{x}^{*}=\left(x_{1}^{*}, \ldots, x_{n}^{*}\right)^{T}$ and $e_{k}^{* L}, e_{k}^{* U}$, for $k=1, \ldots, p$, be an optimal solution to problem (13), where $\mu_{k}^{L}, \mu_{k}^{U}>0$ and $\mu_{k}^{L}+\mu_{k}^{U}=1$ for all $k=1, \ldots, p$. Then, $\mathbf{x}^{*}$ is a possibly efficient solution to problem (2).

Proof. It is apparent that any optimal solution to problem (13) is also an optimal solution to problem (14). If we consider:

$$
v^{*}=\max _{k=1, \ldots, p}\left\{\mu_{k}^{L} e_{k}^{* L}+\mu_{k}^{U} e_{k}^{* U}\right\},
$$

we demonstrate that $\mathbf{x}^{*}$ and $v^{*}$ are also optimal to problem (14) by reductio ad absurdum. Therefore, we assume that this solution is not efficient to (14), and $\overline{\mathbf{x}}=\left(\bar{x}_{1}, \ldots, \bar{x}_{n}\right)^{T}$ and $\bar{v}$ denote an optimal solution to (14). Obviously, this means that:

$$
\begin{array}{r}
\bar{v}+\rho \sum_{k=1}^{p}\left(\mu_{k}^{L}\left(Z_{k}^{L *}-\sum_{j=1}^{n} c_{k j}^{L} \bar{x}_{j}\right)+\mu_{k}^{U}\left(Z_{k}^{U *}-\sum_{j=1}^{n} c_{k j}^{U} \bar{x}_{j}\right)\right)< \\
<v^{*}+\rho \sum_{k=1}^{p}\left(\mu_{k}^{L}\left(Z_{k}^{L *}-\sum_{j=1}^{n} c_{k j}^{L} x_{j}^{*}\right)+\mu_{k}^{U}\left(Z_{k}^{U *}-\sum_{j=1}^{n} c_{k j}^{U} x_{j}^{*}\right)\right) .
\end{array}
$$

According to the constraints of problem (14), we have the following:

$$
\bar{v}=\max _{k=1, \ldots, p}\left\{\mu_{k}^{L}\left(Z_{k}^{L *}-\sum_{j=1}^{n} c_{k j}^{L} \bar{x}_{j}\right)+\mu_{k}^{U}\left(Z_{k}^{U *}-\sum_{j=1}^{n} c_{k j}^{U} \bar{x}_{j}\right)\right\} .
$$

If we consider $\bar{e}_{k}^{L}$ and $\bar{e}_{k}^{U}$ defined as follows:

$$
\begin{array}{ll}
\bar{e}_{k}^{L}=Z_{k}^{L *}-\sum_{j=1}^{n} c_{k j}^{L} \bar{x}_{j,} & k=1, \ldots, p, \\
\bar{e}_{k}^{U}=Z_{k}^{U *}-\sum_{j=1}^{n} c_{k j}^{U} \bar{x}_{j}, & k=1, \ldots, p,
\end{array}
$$

we can say that:

$$
\bar{v}=\max _{k=1, \ldots, p}\left\{\mu_{k}^{L} \bar{e}_{k}^{L}+\mu_{k}^{U} \bar{e}_{k}^{U}\right\} .
$$

Taking into account the constraints of problem (13) imply that:

$$
\begin{array}{ll}
e_{k}^{* L}=Z_{k}^{L *}-\sum_{j=1}^{n} c_{k j}^{L} x_{j}^{*}, & k=1, \ldots, p, \\
e_{k}^{* U}=Z_{k}^{U *}-\sum_{j=1}^{n} c_{k j}^{U} x_{j}^{*}, & k=1, \ldots, p,
\end{array}
$$

From Equations (A1) and (A2) and the definitions of $v^{*}, \bar{e}_{k}^{L}$ and $\bar{e}_{k}^{U}$, it holds that:

$$
\begin{aligned}
& \max _{k=1, \ldots, p}\left\{\mu_{k}^{L} \bar{e}_{k}^{L}+\mu_{k}^{U} \bar{e}_{k}^{U}\right\}+\rho \sum_{k=1}^{p}\left(\mu_{k}^{L} \bar{e}_{k}^{L}+\mu_{k}^{U} \bar{e}_{k}^{U}\right) \\
& <\max _{k=1, \ldots, p}\left\{\mu_{k}^{L} e_{k}^{* L}+\mu_{k}^{U} e_{k}^{* U}\right\}+\rho \sum_{k=1}^{p}\left(\mu_{k}^{L} e_{k}^{* L}+\mu_{k}^{U} e_{k}^{* U}\right) .
\end{aligned}
$$


This contradicts the fact that $\mathbf{x}^{*}, e_{k}^{* U}, e_{k}^{* L}$, for $k=1, \ldots, p$, is an optimal solution to problem (13), given that $\overline{\mathbf{x}}, \bar{e}_{k}^{L}$ and $\bar{e}_{k}^{U}$, for $k=1, \ldots, p$, would be a feasible solution to this problem with an objective value lower than its optimal objective value.

In this regard, the theorem is proven, since we know that every optimal solution to problem (13) is also an optimal solution to (14). According to [37] (Theorem 2), all of this implies that $\mathbf{x}^{*}$ is a possibly efficient solution to the interval MOLP problem (2).

Theorem A3. Let $\mathbf{x}^{*}=\left(x_{1}^{*}, \ldots, x_{n}^{*}\right)^{T}$ and $e_{k}^{* L}, e_{k}^{* U}$, for $k=1, \ldots, p$, be an optimal solution to problem (10), where $\mu_{k}^{L}, \mu_{k}^{U}>0$ and $\mu_{k}^{L}+\mu_{k}^{U}=1$ for all $k=1, \ldots, p$. If the optimal objective value at $\mathbf{x}^{*}$ is 0 , then $\mathbf{x}^{*}$ is a necessarily efficient solution to problem (2).

Proof. The theorem is proven by reductio ad absurdum. Assuming that $\mathbf{x}^{*}$ is not a necessarily efficient solution to problem (2) (i.e., $\mathbf{x}^{*} \notin N_{E}$ ), a necessarily efficient solution for this problem is considered and denoted as $\overline{\mathbf{x}}=\left(\bar{x}_{1}, \ldots, \bar{x}_{n}\right)^{T} \in N_{E}$. By definition, $\overline{\mathbf{x}}$ is efficient for any combination of the objective functions' coefficients in the interval MOLP problem (2); that is, there is no feasible solution which dominates $\overline{\mathbf{x}}$ for any combination of the objective functions' coefficients. Therefore, taking into account that $\mathbf{x}^{*}$ is obviously a feasible solution to problem (2), if we consider, for example, the coefficients $c_{k j}^{L}$ for $k=1, \ldots, p$, $j=1, \ldots, n$ (i.e., the lower bound coefficients), there must exist at least one index $k_{0}$ such that:

$$
\sum_{j=1}^{n} c_{k_{0} j}^{L} x_{j}^{*}<\sum_{j=1}^{n} c_{k_{0} j}^{L} \bar{x}_{j}
$$

Similarly, by using the coefficients $c_{k j}^{U}$ for $k=1, \ldots, p, j=1, \ldots, n$ (i.e. the upper bound coefficients), there must exist at least one index $k_{1}$ such that:

$$
\sum_{j=1}^{n} c_{k_{1} j}^{U} x_{j}^{*}<\sum_{j=1}^{n} c_{k_{1} j}^{U} \bar{x}_{j}
$$

Now, let us assume that for problem (10), the optimal objective value of solution $\mathbf{x}^{*}$ is 0 , that is:

$$
\max _{k=1, \ldots, p}\left\{\mu_{k}^{L} e_{k}^{* L}+\mu_{k}^{U} e_{k}^{* U}\right\}=0 .
$$

Given that $\mu_{k}^{L}, \mu_{k}^{U}>0$ for all $k=1, \ldots, p$, this means that $e_{k}^{* L}=e_{k}^{* U}=0$ for all $k=1, \ldots, p$. Therefore, due to the constraints in (10), it is verified that:

$$
\begin{array}{ll}
0=e_{k}^{* L}=Z_{k}^{L *}-\sum_{j=1}^{n} c_{k j}^{L} x_{j}^{*}, & k=1, \ldots, p, \\
0=e_{k}^{* U}=Z_{k}^{U *}-\sum_{j=1}^{n} c_{k j}^{U} x_{j}^{*}, & k=1, \ldots, p,
\end{array}
$$

which implies that:

$$
\begin{array}{ll}
Z_{k}^{L *}=\sum_{j=1}^{n} c_{k j}^{L} x_{j}^{*}, & k=1, \ldots, p, \\
Z_{k}^{U *}=\sum_{j=1}^{n} c_{k j}^{U} x_{j}^{*}, & k=1, \ldots, p .
\end{array}
$$

On the other hand, according to the definitions of $Z_{k}^{U *}$ and $Z_{k}^{L *}$ given in Section 3.1, the following equations hold for every $\mathbf{x}=\left(x_{1}, \ldots, x_{n}\right)^{T} \in X$ :

$$
\begin{array}{ll}
\sum_{j=1}^{n} c_{k l}^{L} x_{j} \leq Z_{k}^{L^{*}}, & k=1, \ldots, p, \\
\sum_{j=1}^{n} c_{k l}^{U} x_{j} \leq Z_{k}^{U^{*}}, & k=1, \ldots, p .
\end{array}
$$

Taking into account (A6), for every $\mathbf{x}=\left(x_{1}, \ldots, x_{n}\right)^{T} \in X$, this implies that:

$$
\begin{array}{ll}
\sum_{j=1}^{n} c_{k l}^{L} x_{j} \leq \sum_{j=1}^{n} c_{k j}^{L} x_{j}^{*}, & k=1, \ldots, p, \\
\sum_{j=1}^{n} c_{k l}^{U} x_{j} \leq \sum_{j=1}^{n} c_{k j}^{U} x_{j}^{*}, \quad k=1, \ldots, p,
\end{array}
$$


In particular, (A7) holds for solution $\overline{\mathbf{x}}$, so:

$$
\begin{array}{ll}
\sum_{j=1}^{n} c_{k j}^{L} \bar{x}_{j} \leq \sum_{j=1}^{n} c_{k j}^{L} x_{j}^{*}, & k=1, \ldots, p, \\
\sum_{j=1}^{n} c_{k j}^{U} \bar{x}_{j} \leq \sum_{j=1}^{n} c_{k j}^{U} x_{j}^{*}, \quad k=1, \ldots, p,
\end{array}
$$

but this contradicts Equations (A4) and (A5).

In this regard, the theorem is proven and $\mathbf{x}^{*} \in N_{E}$; that is, it is a necessarily efficient solution to the interval MOLP problem (2).

\section{References}

1. Baker, D.P.; Fabrega, R.; Galindo, C.; Mishook, J. Instructional time and national achievement: Cross-national evidence. Prospects 2004, 34, 311-334. [CrossRef]

2. Scheerens, J.; Hendriks, M. State of the art of time effectiveness. In Effectiveness of Time Investments in Education: Insights from a Review and Meta-Analysis; Scheerens, J., Ed.; Springer International Publishing: Berlin/Heidelberg, Germany, 2014; pp. 7-29. [CrossRef]

3. Parhiala, P.; Torppa, M.; Vasalampi, K.; Eklund, K.; Poikkeus, A.M.; Aro, T. Profiles of school motivation and emotional well-being among adolescents: Associations with math and reading performance. Learn. Individ. Differ. 2018, 61, 196-204. [CrossRef]

4. Bonell, C.; Humphrey, N.; Fletcher, A.; Moore, L.; Anderson, R.; Campbell, R. Why schools should promote students' health and wellbeing. BMJ 2014, 348. [CrossRef]

5. Humphrey, N. Social and Emotional Learning: A Critical Appraisal; SAGE Publications Ltd.: Newbury Park, CA, USA, 2013.

6. OECD. PISA 2018 Results; OECD Publishing: Paris, France, 2019.

7. Matthews, N.; Kilgour, L.; Christian, P.; Mori, K.; Hill, D.M. Understanding, evidencing, and promoting adolescent well-being: An emerging agenda for schools. Youth Soc. 2015, 47, 659-683. [CrossRef]

8. Barro, R.J. Human capital and growth. Am. Econ. Rev. 2001, 91, 12-17. [CrossRef]

9. Ereaut, G.; Whiting, R. What do we mean by 'wellbeing'? And why might it matter? Tech. Rep. 2008. Available online: https:/ / dera.ioe.ac.uk/8572/1/dcsf-rw073\%20v2.pdf (accessed on 10 July 2008).

10. Kern, M.L.; Waters, L.E.; Adler, A.; White, M.A. A multidimensional approach to measuring well-being in students: Application of the PERMA framework. J. Posit. Psychol. 2015, 10, 262-271. [CrossRef]

11. OECD2015. PISA 2015 Results in Focus; OECD Publishing: Paris, France, 2018.

12. Bellman, R.; Zadeh, L. Decision making in a fuzzy environment. Manag. Sci. 1970, 17, 141-164. [CrossRef]

13. Goicoechea, A.; Hansen, D.R.; Duckstein, L. Multi-Objective Decision Analysis with Engineering and Business Applications; John Wiley and Sons Publishers: New York, NY, USA, 1982. [CrossRef]

14. Slowinski, R.; Teghem, J. Stochastic Versus Fuzzy Approaches to Multiobjective Mathematical Programming Under Uncertainty; Kluwer Academic Publishers: Dordrecht, Germany, 1990. [CrossRef]

15. Mari, S.I.; Memon, M.S.; Ramzan, M.B.; Qureshi, S.M.; Iqbal, M.W. Interactive fuzzy multi criteria decision making approach for supplier selection and order allocation in a resilient supply chain. Mathematics 2019, 7, 137. [CrossRef]

16. Pérez-Cañedo, B.; Verdegay, J.L.; Concepción-Morales, E.R.; Rosete, A. Lexicographic methods for fuzzy linear programming. Mathematics 2020, 8, 1540. [CrossRef]

17. Wang, C.N.; Nhieu, N.L.; Tran, T.T.T. Stochastic Chebyshev goal programming mixed integer linear model for sustainable global production panning. Mathematics 2021, 9, 483. [CrossRef]

18. Oliveira, C.H.; Antunes, C.H. Multiple objective linear programming models with interval coefficients-An illustrated overview. Eur. J. Oper. Res. 2007, 181, 1434-1463. [CrossRef]

19. Inuiguchi, M.; Kume, Y. Goal programming problems with interval coefficients and target intervals. Eur. J. Oper. Res. 1991, 52, 345-360. [CrossRef]

20. González-Fernández, A.I; Rubio-Misas, M.; Ruiz, F. Goal programming to evaluate the profile of the most profitable insurers: An application to the Spanish insurance industry. Int. Trans. Oper. Res. 2020, 27, 2976-3006. [CrossRef]

21. González-Gallardo, S.; Henriques, C.O.; Marcenaro-Gutierrez, O.D.; Luque, M. A novel approach for exploring the trade-offs between several features of students' well-being. Int. Trans. Oper. Res. 2021. [CrossRef]

22. Yu, J.; McLellan, R.; Winter, L. Which boys and which girls are falling behind? Linking adolescents' gender role profiles to motivation, engagement, and achievement. J. Youth Adolesc. 2021, 50, 336-352. [CrossRef]

23. Demir, Y.; Kutlu, M. Relationships among internet addiction, academic motivation, academic procrastination and school attachment in adolescents. Int. Online J. Educ. Sci. 2018, 10, 315-322. [CrossRef]

24. Ylldırım, S. Teacher support, motivation, learning strategy use, and achievement: A multilevel mediation model. J. Exp. Educ. 2012, 80, 150-172. [CrossRef]

25. Fan, W.; Williams, C. The mediating role of student motivation in the linking of perceived school climate and achievement in reading and mathematics. Front. Educ. 2018, 3, 50. [CrossRef]

26. Allen, K.; Kern, M.L.; Vella-Brodrick, D.; Hattie, J.; Waters, L. What schools need to know about fostering school belonging: A meta-analysis. Educ. Psychol. Rev. 2018, 30,1-34. [CrossRef] 
27. Veenstra, R.; Lindenberg, S.; Oldehinkel, A.J.; De Winter, A.F.; Verhulst, F.C.; Ormel, J. Bullying and victimization in elementary schools: A comparison of bullies, victims, bully/victims, and uninvolved preadolescents. Dev. Psychol. 2005, 41, 672-682. [CrossRef]

28. Athanasiou, K.; Melegkovits, E.; Andrie, E.K.; Magoulas, C.; Tzavara, C.K.; Richardson, C.; Greydanus, D.; Tsolia, M.; Tsitsika, A.K. Cross-national aspects of cyberbullying victimization among 14-17-year-old adolescents across seven European countries. BMC Public Health 2018, 18, 800. [CrossRef]

29. Mischel, J.; Kitsantas, A. Middle school students' perceptions of school climate, bullying prevalence, and social support and coping. Soc. Psychol. Educ. 2020, 23, 51-72. [CrossRef]

30. Oliveira, C.H.; Antunes, C.H. An interactive method of tackling uncertainty in interval multiple objective linear programming. J. Math. Sci. 2009, 161, 854-866. [CrossRef]

31. Henriques, C.O.; Inuiguchi, M.; Luque, M.; Figueira, J.R. New conditions for testing necessarily/possibly efficiency of nondegenerate basic solutions based on the tolerance approach. Eur. J. Oper. Res. 2020, 283, 341-355. [CrossRef]

32. Gabrel, V.; Murat, C.; Remli, N. Linear programming with interval right hand sides. Int. Trans. Oper. Res. 2010, 17, 397-408. [CrossRef]

33. Bitran, G.R. Linear multiple objective problems with interval coefficients. Manag. Sci. 1980, 26, 694-706. [CrossRef]

34. Inuiguchi, M.; Kume, Y. A discrimination method of possibly efficient extreme points for interval multiobjective linear programming problems. Trans. Soc. Instrum. Control. Eng. 1989, 25, 824-826. [CrossRef]

35. Inuiguchi, M.; Sakawa, M. Possible and necessary efficiency in possibilistic multiobjective linear programming problems and possible efficiency test. Fuzzy Sets Syst. 1996, 78, 231-241. [CrossRef]

36. Hladík, M. Complexity of necessary efficiency in interval linear programming and multiobjective linear programming. Optim. Lett. 2012, 6, 893-899. [CrossRef]

37. Henriques, C.O.; Luque, M.; Marcenaro-Gutierrez, O.D.; Lopez-Agudo, L.A. A multiobjective interval programming model to explore the trade-offs among different aspects of job satisfaction under different scenarios. Socio-Econ. Plan. Sci. 2019, 66, 35-46. [CrossRef]

38. Wierzbicki, A.P. The Use of Reference Objectives in Multiobjective Optimization. In Multiple Criteria Decision Making, Theory and Applications; Fandel, G., Gal, T., Eds.; Springer: Berlin/Heidelberg, Germany, 1980; pp. 468-486. [CrossRef]

39. Luque, M.; Marcenaro-Gutiérrez, O.D.; López-Agudo, L.A. On the potential balance among compulsory education outcomes through econometric and multiobjective programming analysis. Eur. J. Oper. Res. 2015, 241, 527-540. [CrossRef]

40. Miettinen, K. Nonlinear Multiobjective Optimization; Kluwer Academic Publishers: Boston, MA, USA, 1999; [CrossRef]

41. Chinneck, J.W.; Ramadan, K. Linear programming with interval coefficients. J. Oper. Res. Soc. 2000, 51, 209-220. [CrossRef]

42. Bannon, S.; McGlynn, T.; McKenzie, K.; Quayle, E. The positive role of Internet use for young people with additional support needs: Identity and connectedness. Comput. Hum. Behav. 2015, 53, 504-514. [CrossRef]

43. Peng, W.; Li, D.; Li, D.; Jia, J.; Wang, Y.; Sun, W. School disconnectedness and adolescent Internet addiction: Mediation by self-esteem and moderation by emotional intelligence. Comput. Hum. Behav. 2019, 98, 111-121. [CrossRef]

44. Wang, W.L.; Kuo, C.Y. Relationships among teachers' positive discipline, students' well-being and teachers' effective teaching: A study of special education teachers and adolescent students with learning disabilities in Taiwan. Int. J. Disabil. Dev. Educ. 2019, 66, 82-98. [CrossRef]

45. Zullig, K.J.; Koopman, T.M.; Huebner, E.S. Beyond GPA: Toward more comprehensive assessments of students' school experiences. Child Indic. Res. 2009, 2, 95-108. [CrossRef]

46. Zullig, K.J.; Huebner, E.S.; Patton, J.M. Relationships among school climate domains and school satisfaction. Psychol. Sch. 2011, 48, 133-145. [CrossRef]

47. Suldo, S.M.; Friedrich, A.A.; White, T.; Farmer, J.; Minch, D.; Michalowski, J. Teacher support and adolescents' subjective well-being: A mixed-methods investigation. Sch. Psychol. Rev. 2009, 38, 67-85. [CrossRef]

48. Salmivalli, C.; Karna, A.; Poskiparta, E. Development, evaluation, and diffusion of a national anti-bullying program, KiVa. In Handbook of Youth Prevention Science; Doll, B., Pfohl, W., Yoon, J., Eds.; Taylor \& Francis Group: Paris, France, 2010. [CrossRef] 